\title{
EL ENGAÑO CONCLUYENTE EN EL DELITO DE ESTAFA*
}

\section{TACIT DECEIT WITHIN FRAUD CRIME}

\author{
LAUra MAYer LuX
}

\begin{abstract}
RESUMEN: El presente trabajo tiene por objeto definir el concepto de engaño concluyente en el delito de estafa. Para ello, se parte de la base de que la estafa es un delito patrimonial, de comunicación y de autolesión, presupuestos teóricos a la luz de los cuales se analizan las nociones de engaño activo y de engaño por omisión. El engaño concluyente es concebido como una forma de engaño activo, caracterizada por la necesidad de llevar a cabo un proceso deductivo del mensaje emitido y cuyo criterio son los elementos que definen la relación negocial de que se trate y sin los cuales esta dejaría de tener sentido. Además, el engaño concluyente es entendido como una afirmación falsa, implícita e indirecta, relativa a hechos típicamente relevantes. Definido el engaño concluyente en la estafa y planteados algunos de sus casos fundamentales, se evalúa la posibilidad de darle reconocimiento en Chile aplicando las normas relativas al delito de estafa contempladas en el Código Penal.
\end{abstract}

Palabras clave: Engaño activo; engaño por omisión; delito patrimonial; delito de comunicación; deducción.

ABSTRACT: This article seeks to define the concept of tacit deceit within the crime of fraud. For this purpose, this study considers fraud as a crime against property, characterized by being a communication offense and a self-damage-crime. With that theoretical framework in mind, this research explains the concepts of active deceit and deceit by omission. It also argues that tacit deceit should be referred as a form of active deceit, characterized by the need to develop a deduction process on the issued message. The criterion used in this deduction process are the elements which define the economic relationship and without which the relationship would lose its meaning. Furthermore, tacit deceit should be interpreted as a false assertion, implicit and indirect, related to fraud-relevant facts. After outlining the definition of tacit deceit and the analysis of its most important cases, this study evaluates the posibility to recognize tacit deceit in Chile, applying the local fraud regulations contained in the Chilean Criminal Code.

Key words: Active deceit; deceit by omission; property offense; communication offense; deduction.

\footnotetext{
" Licenciada en Ciencias Jurídicas, Pontificia Universidad Católica de Valparaíso, Doctora en Derecho, Rheinische-Friedrich-Wilhelms-Universität Bonn, Profesora de Derecho penal, Pontificia Universidad Católica de Valparaíso. Dirección de correo electrónico: laura.mayer@ucv.cl

* Trabajo redactado en el marco del Proyecto Fondecyt No 11121373 "La delimitación del tipo penal de estafa en el ordenamiento jurídico chileno", dirigido por la autora en la Pontificia Universidad Católica de Valparaíso. Cuando se alude a "Código penal" sin otra especificación, se está haciendo referencia al Código penal chileno; cuando se alude a "artículo" sin otra especificación, se está haciendo referencia a un artículo de ese mismo cuerpo normativo.
} 


\section{INTRODUCCIÓN}

El engaño "concluyente" 1 en el delito de estafa ha sido reconocido fundamentalmente en materia de estafa de consumo, cuyo caso más pintoresco es el denominado "perro muerto" ${ }^{2}$, expresión empleada en algunos países latinoamericanos para aludir a quien se retira de un restaurante sin pagar la cuenta de lo que consumió 3 .

El concepto de "engaño concluyente" no se limita al tipo penal de estafa ${ }^{4}$, pese a haber encontrado en él su máxima expresión. Es más, ni siquiera se circunscribe al Derecho Penal, pudiendo extenderse a toda relación comunicativa en la que sea posible construir una afirmación (falsa) mediante un proceso deductivo, afirmación que, por eso mismo, pasará a ser implícita e indirecta. Incluso más allá del concepto de engaño, el Derecho civil de los actos jurídicos reconoce ampliamente la posibilidad de emitir una declaración de voluntad a través de "actos concluyentes" .

Lo que diferencia al engaño concluyente en la estafa de otros engaños concluyentes, es tanto el criterio que ha de utilizarse para efectuar el proceso deductivo, como los hechos a los que debe referirse la afirmación falsa en cuestión ${ }^{6}$. Tratándose de declaraciones concluyentes de voluntad, además del criterio para realizar la deducción y el objeto del mensaje de que se trate, variará el objeto del proceso deductivo mismo: mientras que en el engaño concluyente se deduce una afirmación (falsa) sobre hechos, en las declaraciones concluyentes de voluntad se deduce, precisamente, la voluntad de la parte que la emite ${ }^{7}$.

\footnotetext{
1 "Concluyente" es empleado en el sentido de susceptible de ser deducido. "Deducir", en términos del Diccionario de la Real Academia Española (RAE), denota aquello que permite "sacar consecuencias de un principio, [de una] proposición o [de un] supuesto". En ese orden de ideas KRAATZ (2011) pp. 270 y ss. Que deba realizarse un proceso deductivo para arribar a una proposición determinada es propio de toda construcción conceptual de carácter "concluyente" y, por lo tanto, también del engaño concluyente en la estafa. Véase para ello, por ejemplo, FrisCH (2007) p. 103; SCHMidHäUSER (1983) p. 116, número marginal 10; Vogel (2003) p. 315; también MAYER LuX (2013) pp. 186 y ss., con referencias ulteriores.

2 Aldoney (2010) pp. 78 y ss.; Cabrera y Contreras (2009) p. 87; Hernández (2003) p. 165. Véase también Etcheberry (2010) pp. 397 y ss., así como Garrido Montt (2011) p. 333. Para su reconocimiento en la doctrina española véase, por ejemplo, Bajo Fernández (1987) p. 170, número marginal 34; Choclán Montalvo (2000) pp. 141 y ss., p. 147; Herrero (2000) p. 187.

${ }^{3}$ Como variante de dicho caso se cita a quien, al registrarse en la recepción de un hotel, afirma su solvencia e intención de pagar el importe del servicio contratado [Mestre (2011) p. 299]. Ahora bien, la estafa de consumo en sede hotelera es de ocurrencia cada vez más aislada, atendida la forma usual de pago de esa clase de prestaciones, las más de las veces con tarjeta de crédito y aun antes del registro efectivo en la recepción.

${ }^{4}$ Por el contrario, puede aplicarse, entre otras, a las figuras penales que criminalizan las actividades de colusión o los acuerdos secretos de precios como atentados contra la libre competencia. Estos, no siempre supondrán la comisión de una estafa, delito que solo se verificará si, fuera del engaño, se provoca una disposición patrimonial perjudicial determinada por error.

5 Díez-Picazo (1979) pp. 104 y ss.; Larenz y Wolf (2004) pp. 439 y ss., números marginales 17 y s.; León Hurtado (1991) pp. 27 y ss. Véase, como antecedente de dicha doctrina, Savigny (1840) pp. 242248.

${ }^{6}$ Hechos que, en materia penal, deben tener relación con el bien jurídico subyacente al delito de que se trate.

7 Flume (1979) p. 69, 72 y ss.
} 


\section{ESTADO DE LA CUESTIÓN}

Pese a las diferencias entre el engaño concluyente en la estafa y las declaraciones concluyentes de voluntad en los actos jurídicos, el concepto de engaño concluyente ha sido desarrollado recurriendo a nociones propias del Derecho privado, que poco o nada tienen que ver con las características del tipo penal de estafa, en tanto delito patrimonial, de comunicación y de autolesión.

En la dogmática de la estafa han existido diversas corrientes doctrinales para definir el engaño concluyente. Una de ellas -actualmente superada-, pretendió delimitarlo a través


engaño concluyente recurriendo a la "costumbre" o a los "usos" del tráfico jurídico?. Estas han sido criticadas por sustentarse en elementos eminentemente empíricos ${ }^{10} \mathrm{y}$ de difícil precisión para fijar los contornos de un comportamiento delictivo ${ }^{11}$. A ello se agrega que la noción de costumbre -o de uso- puede aplicarse a cualquier acto comunicativo y, consiguientemente, también a las afirmaciones expresas y aun a conductas omisivas, lo que impide plantearla como algo específico de las aserciones concluyentes.

Igualmente influida por el Derecho privado es la tesis actualmente dominante en Alemania sobre el engaño concluyente en la estafa. En efecto, la mayoría de los autores ${ }^{12}$ y también los fallos del Tribunal Federal alemán ${ }^{13}$, postulan que existe un engaño concluyente cuando el comportamiento ("global") del agente, según la opinión del tráfico jurídico, puede ser entendido ${ }^{14}$ como una declaración ${ }^{15}$ sobre (la existencia o inexistencia) de determinados hechos. La pregunta que surge de inmediato es: ¿qué opina el "tráfico jurídico"? Pregunta cuya sola formulación resulta extraña, pues sugiere que el tráfico jurídico es una suerte de entidad, capaz de formarse un determinado juicio sobre las cosas. Aquí radica la mayor dificultad de esta teoría, a saber, atribuir a la opinión del tráfico una precisión compatible con las exigencias del Derecho penal y que permita arribar a respuestas idénticas frente a los mismos supuestos fácticos ${ }^{16}$. La práctica ha demostrado que la "opinión del tráfico” solo ha servido para que los tribunales alemanes cuenten con una especie de comodín,

8 LaCKNer (1988) número marginal 43; Puppe (1991) p. 573. Véase asimismo Joecks (2010) \$263, número marginal 34.

9 Otto (2005) \$51, número marginal 15; Seibert (2007) p. 352; Tiedemann (2012) número marginal 30, refiriéndose asimismo a la interpretación de "declaraciones expresas".

10 KindHÄUSER (2008) p. 579.

11 MaYer Lux (2013) pp. 155 y ss., con referencias ulteriores.

12 LACKNer (1988) número marginal 28. Véase también, entre otros, DutTGE (2011) \$263, número marginal 10; KÜHL (2011) \$263, número marginal 7; MITSCH (2003) \$7, número marginal 26; RengIER (2011) \$13, número marginal 11.

13 Por todos BGHSt 51, p. 165, 169 y ss.

14 Cramer y Perron (2010) número marginal 12; Wittig (2005) p. 257.

15 De ahí que se diga que tiene un "valor de declaración” (Erklärungswert). Véase, por ejemplo, BocKELMANN (1982) p. 66; GÖSSEL (1996) \$21, número marginal 21; KREY et al. (2012) número marginal 494; WeSSELS y HillenKAMP (2011) número marginal 496.

16 También críticos de recurrir a la opinión del tráfico jurídico para definir el engaño concluyente FRISCH (2007) p. 102 y PAWLIK (1999) p. 97. 
que permite afirmar tanto la existencia como la inexistencia de un engaño concluyente ante idénticos supuestos de hecho ${ }^{17}$.

Hasta ahora, tanto la doctrina penal chilena como la latinoamericana, se han mantenido relativamente ajenas al importante desarrollo que ha experimentado el engaño concluyente en la estafa. Pese a que algunos autores reconocen la existencia de dicha forma de engaño $^{18}$, intentando -en mayor o menor medida- una aproximación a su concepto ${ }^{19}$, el estudio del mismo no ha sido objeto de un análisis exhaustivo, que permita delimitarlo respecto de otros comportamientos, así como dimensionar su específico ámbito de aplicación respecto de dicho tipo penal.

\section{EL CONCEPTO DE ENGAÑO TÍPICO EN EL DELITO DE ESTAFA DESARROLLADO POR LA DOGMÁTICA PENAL IBEROAMERICANA}

\section{a) LA TEORÍA DE LA MISE EN SCÈNE Y DEL ENGAÑO BASTANTE}

En el contexto iberoamericano, el engaño típico en el delito de estafa ha sido entendido tradicionalmente como un comportamiento activo, caracterizado por la realización de una mise en scène o puesta en escena. De acuerdo con dicha tesis, atribuida a la jurisprudencia francesa y seguida por un sinnúmero de fallos chilenos ${ }^{20}$, el engaño en la estafa no puede consistir en una simple mentira: debe implicar un hecho externo o material, "una especie de aparato escénico" 21 destinado a provocar un perjuicio patrimonial a la víctima. No es la sola mentira la que constituye el engaño típico ${ }^{22}$, sino solo aquella que es "reforzada por apariencias objetivas externas" ${ }^{23}$ y que suele denominarse maquinación ${ }^{24}, \operatorname{ardid}^{25} \mathrm{o}$

\footnotetext{
17 Así lo demuestra el vuelco jurisprudencial que experimentó el tratamiento penal de los giros de dinero que efectuaba un cliente respecto de cantidades que el propio banco - sea a través de sus empleados o de los sistemas informáticos que empleaba- contabilizó “erróneamente". Estos supuestos fundamentaron diversas condenas por estafa, al estimarse que el cliente, con el giro del dinero, afirmaba concluyentemente contar con cantidades propias para cubrirlo. El año 2000 comienzan a dictarse fallos que rechazan la concurrencia de una estafa por considerar que el cliente, con el giro del dinero, solo afirma (concluyentemente) su "deseo" de que se dé cumplimiento al giro solicitado. Sea para afirmar o rechazar condenas por estafa, los Tribunales alemanes han recurrido al sentido de la declaración según la "opinión del tráfico jurídico", confirmando la capacidad de adaptación de dicho criterio a toda clase de circunstancias fácticas. Para la jurisprudencia anterior al año 2000 véase, solamente, OLG Celle, StV 1994, p. 188; para la posterior a esa fecha, por ejemplo, BGHSt 46, p. 196, 198 y ss.

18 Balmaceda (2012) pp. 36 y ss.; Mestre (2011) p. 299; Muñoz Conde (2010) p. 432.

19 Aldoney (2010) pp. 77 y ss.; Cabrera y Contreras (2009) pp. 86 y ss.; Hernández (2003) pp. 164 y ss.; Hernández (2012) pp. 154 y ss.; Mañalich (2010) pp. 345 y ss.; Pastor (2010) p. 44; Romero (1998) pp. 138 y ss.; Yubero (2010) pp. 95 y ss.

20 De forma meramente ejemplar Hurtado y otro (1999); Navarro (2001); Vera (2008). Véase asimismo BALMACEDA (2011) p. 63, n. 14, con numerosas referencias relativas a la jurisprudencia chilena.

21 Carrara (1959) p. 426

22 Soler (1956) p. 334. Véase también Bullemore y Mackinnon (2005) p. 128, así como Damianovich (1988) pp. 234 y s.

23 Etcheberry (2010) p. 393

24 Ralda (2002); Vega (2012).

25 Garrido Montt (2011) p. 334.
} 
$\operatorname{artificio}^{26}$. No obstante este planteamiento ha perdido numerosos adeptos dentro de la doctrina $^{27}$, continúa siendo aplicado en una serie de fallos de nuestros Tribunales de Justicia ${ }^{28}$.

Si bien no todos los autores que apoyan la teoría mise en scène plantean que el engaño en la estafa solo pueda ser activo, la exigencia de una puesta en escena parece incompatible con la omisión (impropia) en dicho delito. De otro lado, pese a no existir absoluta claridad respecto del nivel de aparatosidad que ha de requerirse para que el engaño sea típico, tienden a imponerse los planteamientos restrictivos que se contentan con el empleo de (simples) apariencias externas ${ }^{29}$. En cualquier caso, en este razonamiento parece estar envuelta una suerte de prototipo criminológico de "estafador", como un sujeto que embauca a sus víctimas por medio de una representación ${ }^{30}$ más o menos elaborada, similar a un actor que interpreta un determinado papel.

Llevar a cabo una puesta en escena no equivale a realizar "actos concluyentes" ${ }^{1}$. En realidad, el engaño activo en la estafa supone la emisión de una afirmación falsa, la cual puede ser tanto expresa, como concluyente. Oponer el concepto de afirmación expresa mendaz al de "actos concluyentes" - como hace un importante sector de la doctrina ${ }^{32}-$, solo enturbia el concepto de engaño típico. Primero, porque la noción de engaño debe ser analizada en relación con los conceptos de "verdad" o "falsedad", como es propio de toda afirmación (de hechos) ${ }^{33}$ y no de cualquier "acto" o "apariencia externa". Segundo, porque sugiere que el engaño concluyente es una conducta a medio camino entre la acción y la omisión ${ }^{34}$, no obstante tratarse de una forma más de engaño activo ${ }^{35}$.

Por su parte el Código penal español, en el artículo 248.1, exige que la conducta típica en la estafa sea un "engaño bastante" para producir error en el disponente, requisito que también es demandado por un importante sector de la doctrina ${ }^{36}$ y de la jurisprudencia chilena $^{37}$, aun a falta de una disposición legal expresa que lo contemple. Dicha exigencia

26 Lobos (2011) y Vera (2005).

27 Cabrera y Contreras (2009) pp. 44 y ss.; Hernández (2003) pp. 160 y ss.; Mañalich (2010) pp. 345 y ss., n. 9; Ossandón Widow (2010) p. 85; Politoff et al. (2005) pp. 428 y ss.; Schlack (2008) p. 262.

28 Así, por ejemplo, Lobos (2011) y Vega (2012).

29 Bustos (2009) p. 324 (no es necesaria la concurrencia de un "montaje teatral"); Labatut (2012) p. 226; SoLER (1956) pp. 333 y ss.

30 Mestre (2011) p. 299.

31 Pérez Manzano (1995) p. 297, n. 47. De otra forma Bajo Fernández (1987) pp. 168 y s., número marginal 28; Garrido Montt (2011) p. 334; GonzÁlez Rus (2011) p. 488. Véase también Balmaceda y Araya (2010) p. 360 en relación con p. 362.

32 ARZT et al. (2009) \$20, número marginal 32 en relación con número marginal 37; BocKelmANN (1982) pp. 66 y ss.; Yubero (2010) p. 95. Con matices KreY et al. (2012) números marginales 492 y ss.; Muñoz Conde (2010) p. 432.

33 Wellmer (2004) p. 121.

34 Así Maurach et al. (2009) pp. 505 y ss., número marginal 39.

35 Referencias ulteriores en el punto 4. e.

36 Labatut (2012) p. 225, demanda que el engaño sea "suficiente". Así también Herrera (2010) y Piña (2010) p. 103. En la doctrina española véase, por ejemplo, Conde-Pumpido Ferreiro (1997) p. 45; GonzÁlez Rus (2011) p. 486; Rebollo (2008) pp. 111 y ss.

37 Entre otros Álvarez (2008) y Ralda (2002). 
evoca la idea de que el engaño en la estafa debe tener una cierta aptitud o idoneidad ${ }^{38}$ para inducir a error y causar una disposición patrimonial perjudicial ${ }^{39}$, condición que normalmente no lograría satisfacerse con una simple mentira. De esta forma, a un engaño bastan$\mathrm{te}^{40} \mathrm{y}$, por sobre todo, a una puesta en escena, subyace una noción determinada de engaño típico, que no se identifica con cualquier aserción mendaz, sino que solo con una cualifica$\mathrm{da}^{41}$ y compleja ${ }^{42}$, de cierta intensidad ${ }^{43}$, gravedad ${ }^{44}$ y elaboración.

Pese a que algunos autores establecen una relación de sinonimia entre "puesta en escena" y "engaño bastante" 45 , actualmente la doctrina española se encuentra distanciada de dicha vinculación ${ }^{46}$. A diferencia de la tesis de la mise en scène, demandar un engaño bastante desplaza el foco del análisis, desde la representación a cargo del agente, propia de toda puesta en escena, hacia la reacción de cargo del disponente del patrimonio, pues precisamente respecto de dicha reacción el engaño ha de ser "bastante" ${ }^{47}$. Desde este punto de vista, la teoría de la mise en scène desarrolla propiamente un concepto de engaño típico; la tesis del engaño bastante, en cambio, se ubica entre la conducta típica (engaño) y la reacción que esta tiene o puede tener (disposición patrimonial perjudicial determinada por error). Lo anterior, si bien puede fundamentarse en el carácter ambivalente de la noción de "engaño" 48 , acarrea importantes complicaciones en la interpretación del tipo penal de estafa. Al no existir claridad sobre lo que realmente se está definiendo, si el engaño típico del agente o el error del disponente ${ }^{49}$, resulta sumamente difícil distinguir entre el delito consumado y las formas imperfectas de ejecución de la conducta típica, dificultad que será mayor o menor, según la tesis que se adopte para determinar la suficiencia del engaño ${ }^{50}$.

38 Bacigalupo (2007) pp. 167 y ss.; Damianovich (1988) pp. 240 y ss.; Fontán Balestra (2002) pp. 486 y ss.; García Cavero (2010) p. 63; Garrido Montt (2011) p. 334; Vives Antón y González Cussac (2010) pp. 438 y ss.

39 Jiménez de Asúa (2005) p. 322.

40 De otra opinión Mestre (2011) p. 299.

41 Mera (1969) pp. 201 y ss. Similar Aguilar (2008) p. 130 y Silva Silva (2005) p. 39, aludiendo a la "gravedad" o "fuerza" del engaño para influir en el disponente del patrimonio.

42 Ovalle Madrid (2010) p. 96.

43 Choclán Montalvo (2000) p. 89, con referencias ulteriores.

44 Romero (1998) p. 177.

45 Bajo Fernández (1987) pp. 168 y ss., número marginal 28.

46 Arroyo de las Heras (2005) pp. 27 y ss.; Bacigalupo (2007) pp. 167 y ss.; Queralt (2010) p. 492; ReboLLO (2008) pp. 111 y ss.

47 Crítico de este proceder García Rivas (2005) p. 23.

48 Referencias ulteriores en el punto 5.

49 Un razonamiento similar puede verse en Ciano (2006) p. 24 y Hernández (2010 a) p. 12.

50 Las teorías para definir cuándo un engaño es "bastante" se dividen fundamentalmente entre las que atienden a la idoneidad abstracta del comportamiento [Mestre (2011) p. 299], respecto de una persona "medianamente perspicaz y avisada" Muñoz Cuesta, (2003) p. 280 y las que tienen en cuenta las circunstancias concretas de la interacción (comunicativa) entre agente y disponente [BAJO FERnÁNDEZ (1987) pp. 169 y s., números marginales 29 y s.; Quintero Olivares (2011) p. 666; Tocora (1991) p. 109. Con matices Fontán Balestra (2002) p. 487]. En cambio, considerar que el engaño sea bastante solo si efectivamente provoca un error en el caso concreto no es una teoría viable. No solo porque impediría distinguir el error del engaño -cuestión a la que más de alguien puede atribuir un valor meramente analítico-, sino también, porque volvería prácticamente imposible el castigo de formas imperfectas de ejecución de la conducta típica. En sentido análogo BaLmaCEDA (2011) p. 71. 
La exigencia de un engaño bastante o suficiente no se opone necesariamente al engaño por omisión. Esta compatibilidad conceptual preliminar entre engaño bastante y omisivo, unida a la consagración positiva de una cláusula general de comisión por omisión en el artículo 11 del Código penal español, podrían conformar la base de un fructífero desarrollo de las posiciones de garante en el tipo penal de estafa. Pese a ello, la estafa por omisión ha sido resistida por la doctrina española mayoritaria ${ }^{51}$ que, en todo caso, tiende a confundir supuestos de omisión con casos que, en realidad, son de engaño concluyente ${ }^{52}$ y, consiguientemente, de engaño activo.

\section{b) LA TEORÍA DE LA SIMPLE MENTIRA}

De forma más reciente y en parte como reacción ante la falta de una exigencia legal expresa de que el agente lleve a cabo, ineludiblemente, una puesta en escena o emita un engaño bastante, se ha ido extendiendo la tesis que no excluye la simple mentira como forma de engaño típico en el delito de estafa ${ }^{53}$. Por el contrario, se ha sostenido que en determinados supuestos, una simple mentira bastará o será suficiente para constituir un engaño típico; ${ }^{54}$ en otros casos, en los que el legislador exija engaños calificados, tendrá que emitirse algo más que una simple mentira y efectuarse, en cambio, un ardid o maquinación ${ }^{55}$. De esta manera, la teoría de la simple mentira amplía las conductas que pueden ser consideradas como engaño típico para efectos de la estafa, a diferencia de lo que ocurre con las tesis restrictivas del engaño bastante $\mathrm{y}$, sobre todo, de la mise en scène.

Un sector de la doctrina chilena intenta reforzar la teoría de la simple mentira, indicando que algunas disposiciones del Código penal relativas al delito de falsedad, imponen sancionar a título de estafa $-\mathrm{y}$ no de acuerdo con las falsedades- a aquellas falsificaciones groseras, ostensibles, mal ejecutadas o burdas ${ }^{56}$. Dicha consideración, que más se vincula con la teoría del engaño bastante que con la de la mise en scène ${ }^{57}$, pone de relieve un divorcio entre el Derecho positivo chileno y la doctrina penal relativa al delito de estafa que, obstinada con distinguir en forma excluyente el "verdadero" fraude penal constitutivo de estafa $^{58}$ del meramente civil ${ }^{59}$, ha postulado exigencias típicas en parte asistemáticas, en parte alejadas del bien jurídico que está a la base de dicho tipo delictivo.

51 Fundamental Pérez del Valle (1996) pp. 373 y ss. Véase también Muñoz Conde (2010) p. 432.

52 Bustos (2009) p. 326 y Queralt (2010) p. 494. Véase asimismo Silva Silva (2005) p. 43. Destaca las diferencias entre ambas formas de engaño, en cambio, Valle Muñız (1986) pp. 865 y ss.

53 Con más o menos matices, por ejemplo, Ciano (2006) p. 24; Donna (2001) p. 278, p. 283, p. 293; FERNÁNDEZ (2005) p. 185; FinZI (1961) p. 41; PIÑA (2006) pp. 52 y ss.

54 Creus (1999) p. 468. En contra Dayenoff (2003) p. 251.

55 Politoff et al. (2005) pp. 443 y ss.

56 Contreras (1992) pp. 40 y ss.; Hernández (2003) pp. 161 y ss. De otra opinión Garrido Montt (2011) p. 335.

57 Ya que una puesta en escena puede ser burda [Mera (2005) p. 57], pero para que un engaño sea "bastante", no hay mucho espacio para falsificaciones groseras, ostensibles, mal ejecutadas o burdas.

58 Arroyo de las Heras (2005) p. 27.

59 Distinción excluyente que Hernández (2003) p. 158, califica de “mito". Véase también BalmaCEDA (2011) pp. 69 y ss.; García Rivas (2005) p. 29 y ss.; Soto (1993) p. 15. La efectúan, en cambio, con más o menos matices, por ejemplo, Bullemore y Mackinnon (2005) p. 127; Choclán Montalvo (2000) pp. 89 y ss.; EtCheberry (2010) pp. 394 y s.; Labatut (2012) p. 227; Yubero (2010) pp. 87 y ss. 
La doctrina chilena está en lo correcto cuando afirma que de las normas del Código Penal no se desprende una exigencia general de que el agente lleve a cabo una puesta en escena. La posibilidad de subsumir como formas de engaño típico a falsificaciones burdas, se opone a una demanda general de que se ejecute un engaño bastante, a las cuales, en todo caso, puede pronosticárseles alcanzar una forma imperfecta de ejecución del delito respecto de un importante número de casos. Con todo, sostener que el engaño típico en la estafa equivalga o pueda equivaler a una "mentira", requiere efectuar una serie de precisiones que ponen en duda las reales ventajas de tal formulación del comportamiento incriminado.

El concepto de mentira tiene una connotación moral ${ }^{60}$ y aun religiosa, que lo aleja del tipo penal de estafa en tanto delito patrimonial por antonomasia ${ }^{61}$. La idea de que la mentira sea "pecado" o de que exista un deber moral de no mentir ${ }^{62}$ o de ser "veraz", está muy lejos de posibilitar una aproximación adecuada a la conducta delictiva en la estafa. A ello se agrega que una mentira, en tanto acto comunicativo, supone simplemente un hablante, que la emite, y un oyente, que recibe e interpreta el mensaje falaz de que se trate. En cambio, el comportamiento típico en la estafa va más allá de eso, perfilándose como un medio de lesión del patrimonio de otro ${ }^{63}$. No por nada la doctrina penal alude al "engaño" típico y no a la "mentira" típica como comportamiento incriminado. Solo el "engaño" típico -y no la "mentira" - es un medio de lesión del patrimonio ajeno en el delito de estafa ${ }^{64}$.

\section{BASES PARA LA DEFINICIÓN DEL ENGAÑO CONCLUYENTE EN EL DELITO DE ESTAFA}

\section{a) LA ESTAFA COMO DELITO PATRIMONIAL, DE COMUNICACIÓN Y DE AUTOLESIÓN}

La estafa es un delito contra el patrimonio ${ }^{65}$. Más precisamente, constituye un delito de "lesión" 66 a los "intereses patrimoniales" ${ }^{67}$ de otro. Algunos autores han llegado a afirmar que la estafa es el más relevante de los delitos contra intereses patrimoniales ${ }^{68}$. En realidad la estafa, junto con el hurto, forman los pilares sobre los que se cimientan los delitos contra

\footnotetext{
60 Adam (1927) p. 158; Richter (2005) p. 80; asimismo Calle Rodríguez (1998) pp. 22 y ss.

${ }^{61}$ Gaede $(2011) \$ 263$, número marginal 1; Zugaldía Espinar (1988) p. 53. Véase también Fernandes GodINHO y MAYer LuX (2011) pp. 237 y ss.; Rengier (2011) \$13, número marginal 1; Vives ANTÓN y GonZÁLEZ Cussac (2010) p. 435.

62 Bustos (2009) p. 325.

63 Bockelmann (1982) p. 63; Contreras (1992) p. 12; Maass (1982) p. 33; Rodríguez Devesa y Serrano Gómez (1995) p. 499; Vargas (2010) p. 57. Véase asimismo Becker (1948) p. 50 y Dayenoff (2003) p. 248.

${ }^{64}$ Binding (1902) p. 341, 344.

65 Fundamental Merkel (1971) pp. 56 y ss. Véase también Aguilar (2008) p. 129; Fanelli (2009) p. 58; Grisolía (1997) pp. 417 y ss.; KüHL (2011) \$263, número marginal 2; Rebollo (2008) p. 94; Valle MuñIZ (1989) p. 84. Con matices Gallego Soler (2005) pp. 550 y ss.

66 Bung (2007) p. 369; Damianovich (1988) p. 229; Quintero Olivares (2011) p. 666; SchmidhäUser (1983) p. 115, número marginal 7; SOler (1956) p. 332; VARGAS (2010) p. 52.

67 Gössel (1996) \$21, número marginal 1; Rivacoba (1992) pp. 17 y ss., a propósito del delito de contrato simulado.

68 Rengier $(2011) \$ 13$, número marginal 1; WitTIG (2011) \$14, número marginal 1.
} 
intereses de índole patrimonial, regulados en el Título IX del Libro II del Código Penal chileno.

Que la estafa sea un delito patrimonial hace necesario delimitar los hechos que pueden ser objeto del engaño típico. A lo anterior se agrega la relación que ha de tener el engaño con la disposición patrimonial perjudicial determinada por error, relación que se sustenta en dos características estrechamente vinculadas de la estafa, que la distinguen de cualquier otra figura de la Parte Especial: ser un delito de comunicación ${ }^{69}$ y de autolesión ${ }^{70}$.

La estafa, como ningún otro delito, se basa en la existencia de una interacción comunicativa en la que se produce un intercambio de información entre dos individuos: el agente y el disponente del patrimonio. Ello implica no solo la emisión de un mensaje comunicativo -cuestión por lo demás común a todo delito que deba ser cometido a través de un acto de habla-, sino también una reacción de parte del destinatario del mensaje, como consecuencia de su recepción e interpretación de la información proporcionada ${ }^{71}$.

La realización del acto de disposición patrimonial presupone que el disponente cuente con información de relevancia para la relación negocial que se verifica entre él y quien lo engaña. Para que pueda sancionarse a este último, ya no por una simple disposición patrimonial, sino por aquella que es perjudicial y determinada por el error que es fruto del engaño ${ }^{72}$, es necesario -en términos negativos- que el agente no proporcione una información típicamente relevante al disponente, lo cual puede obedecer, o bien a que el agente realizó una afirmación falsa (engaño activo), o bien, a que no realizó una afirmación verdadera debida (engaño por omisión).

En el delito de estafa, el engaño es el primer eslabón de una cadena de elementos ${ }^{73}$ causalmente vinculados $^{74}$, a saber: engaño, error, disposición patrimonial y perjuicio patrimonial $^{75}$. El engaño en la estafa, además, es el medio del que se vale el autor del delito para instrumentalizar al disponente y provocar el perjuicio patrimonial de este o de un tercero. Solo debido a que el agente instrumentaliza al disponente del patrimonio ${ }^{76}$, este termina ejecutando un comportamiento patrimonialmente perjudicial que, de no haber mediado un engaño típico, no se verificaría ${ }^{77}$. De ahí que sea más exacto aludir a una "autolesión

69 Fundamental Tiedemann (2012) número marginal 4. Véase asimismo Ellmer (1986) p. 120; Hefendehl (2006) número marginal 21; KASISKE (2009) p. 365; TÖNNies (1971) p. 61; Walter (1999) p. 43.

70 Fundamental Frisch (1979) pp. 657 y ss.; también Creus (1999) p. 462; Donna (2001) p. 280; DutTGE (2011) \$263, números marginales 2 y 27; Hernández (2010 b) pp. 36 y ss.; Labatut (2012) p. 225.

71 Similar LAPORTA (2013) pp. 192 y ss., comparando la estructura de la estafa con la del delito tributario.

72 Ossandón Widow (2010) p. 89.

73 FisCHER $(2011) \$ 263$, número marginal 5 y GÖsSEL (1996) \$21, número marginal 5 . En sentido análogo BaCigalupo (2007) p. 165.

74 Cramer y Perron (2010) número marginal 5; Etcheberry (2010) p. 392; Grisolía (1997) p. 420; HernÁndez (2003) p. 150; Yubero (2010) p. 44. Con matices Politoff et al. (2005) p. 418. De otra opinión Piña (2006) p. 47 (“relación normativa”).

75 Antón Oneca (1958) p. 57. Véase asimismo Cabrera y Contreras (2009) pp. 31 y ss.; Finzi (1961) pp. 59 y s.; Mitsch (2003) \$7, número marginal 16; Romero (1998) p. 113.

76 Choclán Montalvo (2000) p. 21; Kühl (2011) \$263, número marginal 22; también Peña (2010).

77 Ovalle Madrid (2010) p. 99. Véase asimismo Fernández (2005) p. 184. 
imputable al agente"78, sin perjuicio de los casos de estafa triangular, en que el término "autolesión" debe entenderse en un sentido figurado.

Para que en la estafa se produzca la lesión patrimonial, el agente requiere una "contribución" del disponente "a la realización del tipo", contribución que, a diferencia de lo que acontece en los delitos de heterolesión -vgr. el hurto-, aquí resulta "necesaria, constitutiva, y no meramente contingente"79. De esta forma, la víctima "colabora" ${ }^{80}$ con el sujeto activo del delito "como instrumento de su propio daño" ${ }^{1}$. Lo particular de la autolesión propia de la estafa es su carácter -más o menos- inconsciente ${ }^{82}$, que se vincula con la noción de engaño como "medio no violento" para provocar una disposición patrimonial perjudicial determinada por error ${ }^{83}$. Quien efectúa una disposición patrimonial en la estafa lo hace creyendo (equivocadamente) que lleva a cabo un comportamiento patrimonialmente conveniente ${ }^{84}$, a diferencia de la autolesión que podría darse en otras figuras, como la extorsión, en que el sujeto pasivo "dispone" porque es obligado mediante violencia o intimidación ${ }^{85}$.

\section{b) El OBJETO DEL ENGAÑO EN EL DELITO DE ESTAFA: HECHOS TÍPICAMENTE RELEVANTES}

Todo acto de habla se refiere a un hecho, esto es, a algo que sucede en el mundo exterior o interior del individuo. Sea que se lleve a cabo una amenaza, una calumnia o una aserción, el objeto de las mismas será un hecho, "algo" a lo que alude la amenaza (vgr. Juan le dice a su hermano: "Uno de estos días te voy a matar"), la calumnia (por ejemplo, Juan le dice a la prensa, luego de haber dado muerte a su hermano: "María mató a mi hermano esta mañana”) o la afirmación (vgr. María le dice a la prensa: "Yo no maté al hermano de Juan").

Un juicio de valor, en tanto acto de habla, también se refiere a un hecho ${ }^{86}$. Su exclusión como forma de engaño típico obedece a la imposibilidad de sostener que una opinión

\footnotetext{
78 De forma análoga Matus (2012) p. 328.

79 Hernández (2010 a) p. 21. Asimismo Gauger (2001) pp. 203 y ss.

80 Gutiérrez Francés (2010) p. 6. Similar García Rivas (2005) p. 36.

81 Choclán Montalvo (2000) p. 21.
}

82 Maurach et al. (2009) p. 498, número marginal 11. También Pérez Manzano (1995) p. 292, n. 22 y n. 23 ; Rodríguez Devesa y Serrano Gómez (1995) p. 507. Esta idea se diferencia de la consciencia o inconsciencia respecto del acto de disposición patrimonial. Pues una cosa es saber que lesiono mi patrimonio y otra, que estoy disponiendo de él. Sobre el punto véase, por ejemplo, Bacigalupo (2007) p. 173; Cramer y Perron (2010) número marginal 60; KINDHÄUSER (2013) número marginal 223.

83 Choclán Montalvo (2000) p. 87.

84 Gallego Soler (2005) pp. 544 y s.

85 HruschKa (2002) pp. 452 y ss. En ella, de acuerdo con el artículo 438 del Código penal chileno, la víctima es obligada mediante violencia o intimidación a suscribir, otorgar o entregar un documento que importe una obligación estimable en dinero. Tanto en la estafa, como en la extorsión, hay una instrumentalización del sujeto pasivo, pero mientras en la primera el disponente actúa creyendo (equivocadamente) en la efectividad de la información típicamente relevante con la que cuenta, en la segunda el extorsionado lleva a cabo el comportamiento establecido en el tipo, consciente de su sentido y producto de la coacción de la que ha sido objeto. De ahí que Soler (1956) p. 332, afirme, que la voluntad del extorsionado está viciada por coacción o intimidación, mientras que la del disponente en la estafa, por error. Asimismo ANTÓN ONECA (1958) p. 57. Una excepción a este carácter autolesivo de la extorsión es el supuesto en que se obliga a la víctima a entregar un documento y en que el sujeto activo lleva a cabo un comportamiento apropiatorio equivalente al robo. Véase para ello, solamente, Oliver (2013) pp. 368 y ss., con referencias ulteriores.

86 MÜller (1981) p. 257. 
sea "verdadera" o "falsa" en el sentido en que se emplean dichos términos respecto de una afirmación ${ }^{87}$, y no a que se "oponga" al concepto de hecho. Es lo que acontece, por ejemplo, si alguien dice que "la novena sinfonía de Beethoven es la obra musical más hermosa que conoce la historia de la humanidad". Ahora bien, el sentido específico que asuma un determinado acto de habla o, dicho de otro modo, su "fuerza ilocucionaria" depende, en todo caso, del contexto en el que se lleve a cabo la interacción comunicativa en cuestión. Quién emite el mensaje, cómo lo emite y respecto de quién lo emite puede ser más relevante que las palabras empleadas por el emisor ${ }^{88}$.

El concepto de "verdad" no puede atribuirse a una afirmación en cuanto tal, esto es, aisladamente considerada. Para determinar si una afirmación es "verdadera" o "falsa" debe considerarse la relación que se da entre la afirmación de que se trate, los individuos que intervienen en la interacción comunicativa y el contexto espacio-temporal en el que esta interacción se desenvuelve ${ }^{89}$. Ello permite que frente a un cambio en las circunstancias en las que se lleva a cabo una determinada aserción, la afirmación que en un contexto era falsa pase a ser verdadera en otro y que la que era verdadera, se torne falsa ${ }^{90}$.

Plantear que el engaño típico debe referirse a un hecho ${ }^{91}$ no pasa de ser una trivialidad, puesto que todo acto de habla ha de tener "algo" como objeto de referencia. Lo interesante es determinar, dentro de todos los posibles hechos a los que puede referirse una afirmación, aquellos que tienen relevancia en relación con el comportamiento típico. Para lograrlo, debe tenerse en cuenta, fundamentalmente, el bien jurídico subyacente al tipo delictivo en cuestión.

Siendo el engaño en la estafa un medio de lesión de intereses patrimoniales ajenos, la connotación patrimonial de los hechos a los que ha de referirse el engaño resulta ineludible y debe ser categórica. Por consiguiente, serán hechos típicamente relevantes para el delito de estafa aquellas circunstancias que, de acuerdo con la relación negocial concreta que se verifique entre el agente y el disponente, sean manifiestamente determinantes para efectuar una disposición patrimonial racional ${ }^{92}$.

En el tipo penal de estafa, tanto el engaño activo como el omisivo ${ }^{93}$ deben referirse a hechos típicamente relevantes ${ }^{94}$. De lo que se trata es de que se comunique (engaño activo) un mensaje de relevancia para la disposición patrimonial de su receptor, que le permita

87 De otra opinión García Rivas (2005) p. 27.

88 Giese (1992) p. 3; Habermas (1995) p. 373; Kern (1919) pp. 40 y ss., 75 y ss.; KindhäUser (2008) p. 584; Weinrich (2006) pp. 29 y ss., p. 37. Véase también MAYER LuX (2013) p. 80, con referencias ulteriores.

89 Davidson (2009) p. 43.

90 Así, por ejemplo, afirmar que un determinado producto es el más eficiente de su clase, puede ser hoy verdadero, pero en unos años falso, si es que otro producto lo desplaza del mercado en tal atributo.

91 Bacigalupo (2007) p. 166; Binding (1902) p. 346; Bockelmann (1982) p. 65; Choclán Montalvo (2000) p. 97; Gössel (1996) \$ 21, número marginal 9; KÜHL (2011) \$263, número marginal 4; Отто (2005) \$51, número marginal 9.

92 Con matices respecto de lo que aquí se plantea KindHÄUSER (2013) número marginal 75. Véase también Frisch (2008) p. 741; Kühne (1978) pp. 9 y ss.; PASTOR (2004) pp. 188 y ss., p. 193. En cambio, critican la restricción del objeto del engaño típico Vives Antón y GonzÁlez Cussac (2010) p. 439.

93 García Rivas (2005) p. 25; Grima Lizandra (2005) pp. 48 y ss.

94 Con mayor amplitud que lo que aquí se plantea MaUrach et al. (2009) p. 510, número marginal 49. 
decidir sobre si disponer o no del patrimonio, contando con los elementos indispensables para ello según la relación negocial en cuestión. O bien, de no comunicar (engaño por omisión) un mensaje de relevancia para la disposición patrimonial, pese a haber debido y serle exigible a quien omitió la emisión del mensaje ${ }^{95}$.

La relevancia de un determinado hecho depende del contexto particular en el que se desarrolle la interacción comunicativa entre el agente y el disponente del patrimonio. En el delito de estafa, qué circunstancias específicas sean relevantes para un concreto acto de disposición patrimonial variarán de una relación negocial a otra, según cuáles sean los elementos fundamentales que la definan ${ }^{96}$.

\section{c) IMPORTANCIA DE LA DISTINCIÓN ENTRE ACCIÓN Y OMISIÓN PARA LA DEFINICIÓN DEL} ENGAÑO TÍPICO EN LA ESTAFA

Durante mucho tiempo la doctrina sostuvo que el engaño en la estafa constituía una forma de conducta eminentemente activa ${ }^{97}$. Ello venía a confirmar la regla imperante respecto de los comportamientos delictivos de la Parte Especial, descritos ante todo como figuras activas y no como tipos omisivos. Fuera de los escasos delitos descritos en términos omisivos, una excepción a este estado de cosas fue el homicidio (o infanticidio) que comete la madre (o el padre) que no alimenta a su hijo. Dicho supuesto parecía exento de mayores reparos, tanto porque "matar a otro" resultaba compatible con la omisión ${ }^{98}$, como porque

\footnotetext{
95 Que tanto el engaño activo como el omisivo deban referirse a hechos típicamente relevantes, permite superar las dificultades que provoca la denominada "cláusula de equivalencia" en la comisión por omisión. La doctrina comparada critica la exigencia de que la omisión "equivalga" a la realización activa del tipo, así como la interpretación que muchos autores le han dado a ese requisito. En cuanto a lo primero, se dice que si se da una posición de garante en el agente, la omisión (impropia) ya habrá cumplido con aquello que permite considerarla un injusto equivalente a la acción lesiva [en sentido análogo SCHÖNE (1974) p. 339]. Respecto de la interpretación de la cláusula de equivalencia, afirmar que existe una equivalencia entre acción y omisión cuando se es garante del bien jurídico implica confundir dos exigencias que deben ser entendidas y demandadas separadamente [así Kargl (2007) p. 279]. Para superar dichas dificultades puede recurrirse a los hechos que deben ser referencia del engaño típico. De esta forma, habrá estafa omisiva -al menos en aquellos países que la consagran normativamente- si el agente, además de ser garante del bien jurídico, no efectúa una afirmación verdadera debida sobre hechos típicamente relevantes, pues solo respecto de tales hechos es posible sostener una equivalencia entre el injusto activo y el injusto omisivo [MAYER LuX (2013) p. 214].

96 La idea de relevancia de un determinado hecho también se plantea respecto de otras instituciones jurídicas. Es lo que acontece, por ejemplo, con el denominado "consentimiento informado" al que se refiere el Código de Ética del Colegio Médico de Chile y que debe concurrir frente a toda intervención en el ámbito sanitario. Para que el consentimiento otorgado sea "informado", el paciente ha de estar al tanto de todos aquellos elementos particulares e indispensables para decidir someterse a determinada intervención, conociendo sus riesgos específicos, los procedimientos alternativos, el tiempo de convalecencia, entre otros. De ahí que varíe la información relevante que se dará a quien se someta a la extracción de un tumor cerebral, de la que se entregará a quien simplemente se le extirpará un lunar cutáneo.

97 Con referencia al delito de estafa NaUCKe (1964) pp. 106 y ss., p. 214. Véase también GrÜNWALD (1966) p. 291 y MAYER (1953) p. 152, así como Bajo FERnÁNdez (1987) p. 170, número marginal 34 y ContreraS (1992) p. 64.

98 Compatibilidad que generalmente se excluye respecto de los delitos de mera actividad, como la violación [cfr. solamente Rodríguez Collao (2004) p. 163] y el hurto [véase, por todos, Oliver (2013) pp. 122 y ss.], que la doctrina ha interpretado como conductas activas, tanto por oponerse conceptualmente a la infracción de un mandato de actuar, como por no exigir en la descripción legal un resultado típico diverso de la conducta y
} 
se afirmaba una gravedad similar de ambas especies de conducta. En ese orden de ideas, no se vislumbraba una distinción categórica a nivel de injusto entre la madre (o el padre) que mata a su hijo por asfixia (acción) y la madre (o el padre) que lo hace por inanición (omisión) ${ }^{99}$.

La importancia que han ido adquiriendo los intereses patrimoniales en las disposiciones penales chilenas, podría dar pie al castigo de la estafa en su modalidad omisiva. Si el resultado del engaño activo y del engaño por omisión es idéntico, a saber, la disposición patrimonial perjudicial determinada por error, no se advierte entonces qué diferencia de fondo podría existir entre quien daña el patrimonio ajeno porque efectuó una afirmación falsa sobre hechos típicamente relevantes y quien daña el patrimonio ajeno porque no proporcionó información típicamente relevante que debía y podía entregar.

La estafa omisiva, sin embargo -al igual que el homicidio (o infanticidio) por omisión-, enfrenta una dificultad insuperable: la falta de certeza que provoca el fundamento del castigo en consideraciones doctrinales que, por arraigadas que estén, no obligan al juez. De ahí que en los ordenamientos jurídicos que no cuenten con una cláusula general de comisión por omisión, como es el caso chileno, resulte ineludible una consagración legal de la misma. El castigo de la omisión impropia no debe depender del Tribunal que la juzgue, sino que ha de basarse en normas que posibiliten una interpretación mínimamente estandarizada de (todos) los tipos penales de la Parte Especial ${ }^{100}$. Mientras ello no ocurra, la sanción de la estafa omisiva seguirá en una suerte de limbo. Lo anterior confirma la importancia que tiene distinguir entre el engaño activo y el omisivo ${ }^{101} \mathrm{y}$, ante todo, entre el engaño por omisión y el engaño concluyente como formas de conducta típica.

\section{d) El CONCEPTO DE AFIRMACIÓN COMO EJE DE LA DistinCión CONCEPTUAL ENTRE ENGAÑO ACTIVO Y ENGAÑO OMISIVO \\ El engaño (activo) es, ante todo, una afirmación falsa sobre determinados hechos ${ }^{102}$.} Si tuviéramos que ubicar al engaño dentro de alguna categoría de acto de habla, diríamos que el engaño es un acto de habla asertivo, caracterizado porque la aserción realizada es

unido a esta mediante un vínculo causal que permita, de acuerdo con la tesis tradicional, construir un supuesto de comisión por omisión.

99 Silva SÁnchez (2003) p. 451. Probablemente el hecho de centrar el foco en el resultado (muerte del niño) y no en el comportamiento típico (acción u omisión) se vio reforzado por la relevancia que ha tenido el bien jurídico "vida" en los ordenamientos penales occidentales.

100 Incluso del homicidio por omisión, pues basar su sanción punitiva en la relevancia del bien jurídico "vida", no solo puede ser discutido en atención al curso que ha tomado la normativa penal en Chile, sino porque la relevancia del objeto jurídico de tutela no supera el problema insalvable de la falta de consagración expresa de la comisión por omisión y, consiguientemente, de la infracción al principio de legalidad que supone su castigo en Chile. En Latinoamérica, la ausencia de una cláusula general que permita castigar penalmente la omisión impropia ha sido parcialmente subsanada en el último tiempo. Así, por ejemplo, en los ordenamientos jurídicos colombiano (artículo 25 del Código penal de Colombia) y peruano (artículo 13 del Código punitivo del Perú). Sobre el problema de la estafa por omisión en Chile véase solamente Cabrera y Contreras (2009) pp. 87 y ss., con referencias ulteriores.

101 De otra opinión Bacigalupo (2007) p. 170; PAstor (2004) pp. 218 y ss.; PAWlik (1999) p. 97.

102 Bockelmann (1982) pp. 65 y s.; Fischer (2011) $\$ 263$, número marginal 7; GÖsSEL (1996) $\$ 21$, números marginales 12 y 15; KINDHÄUSER (2013) número marginal 108. 
contraria a la verdad ${ }^{103}$. Quien realiza una afirmación transmite a su interlocutor una convicción, a saber, que el emisor del mensaje de que se trate cree que lo aseverado es efectivo $^{104}$. Esto permite que el receptor de dicho mensaje pueda basar sus decisiones sucesivas en la creencia de que lo afirmado es cierto. Consiguientemente, una afirmación es capaz de generar una expectativa de veracidad en quien recibe e interpreta el mensaje asertivo. Ahora bien, que el emisor de la afirmación transmita dicha convicción no equivale a que efectivamente la tenga, es decir, no equivale a que crea que su aserción es verdadera. Precisamente quien engaña a otro comunica una convicción que no tiene ${ }^{105}$ y que se opone al contenido de la proposición que realiza.

Definir al engaño como una afirmación falsa sobre hechos posibilita, entre otras cosas, distinguir entre un engaño y otros actos de habla que no pueden ser valorados como verdaderos o falsos, vgr. los juicios de valor ${ }^{106}$. El engaño no es "cualquier conducta que, influyendo en la representación intelectual de otro, le conduzca a una falsa idea de la realidad o lo mantenga en ella"107 sino solo una afirmación falsa sobre hechos típicamente relevantes. A ello se agrega que dicha definición de engaño permite superar las enormes dificultades que provoca el concepto de engaño bastante o suficiente. En este orden de ideas, si el agente efectúa una afirmación falsa sobre hechos típicamente relevantes, la fuerza (ilocucionaria) del concepto de afirmación, unida a la connotación patrimonial de los hechos a que debe referirse el engaño, provocará que su comportamiento sea un engaño típico, sin necesidad de plantear ulteriores exigencias de idoneidad y permitiendo fundamentar el castigo penal a lo menos de una forma imperfecta de ejecución del delito de estafa.

La distinción entre engaño por acción y engaño por omisión en la estafa implica diferenciar entre dos clases de normas, a saber, prohibiciones (de acciones) y mandatos (de acciones ${ }^{108}$. Así, mientras que el engaño activo supone realizar una afirmación falsa prohibida, el engaño por omisión implica no realizar una afirmación verdadera mandada, no obstante haber sido esta posible y exigible de ejecutar ${ }^{109}$. Sea en su vertiente activa u omisiva, el concepto de afirmación es constitutivo del engaño típico ${ }^{110} \mathrm{y}$, además, la base para distinguir entre acción y omisión en la estafa. A partir de estas consideraciones es posible sostener, que si bien la estafa es un delito de "medios determinados", ya que solo puede

\footnotetext{
103 FalKenberg (1982) pp. 99 y ss., p. 106; Giese (1992) pp. 84 y s.; GreWendorf (1982) p. 128; HungerLAND (1979) pp. 275 y ss.; SEARLE (1999) pp. 9 y ss.

104 Davidson (2009) p. 270; Tugendhat (1976) p. 270; Williams (2004) pp. 79 y ss.

105 FalKenberg (1982) p. 131.

106 Con especial referencia a la estafa Aldoney (2010) p. 80 y Choclán Montalvo (2000) p. 97. Con un alcance más amplio Davidson (2004) p. 39, p. 42; Hruschka (1988) p. 425; Puppe (2008) p. 22.

107 Politoff et al. (2005) p. 424. Dicho concepto se basa en Cramer y Perron (2010) número marginal 6, y es reiterado por Matus (2013) p. 332. Véase igualmente Aguilar (2008) pp. 129 y ss., así como ArZT et al. (2009) \$20, número marginal 35; Balmaceda (2010) p. 17; Bullemore y Mackinnon (2005) p. 128.

108 Respecto de la estafa MaAss (1982) p. 33. Con un alcance más amplio Vogel (1993) p. 34.

109 Fischer (2011) \$263, número marginal 38; KINDHÄUSER (2013) número marginal 152; KüHL (2011) \$ 263, número marginal 13.

110 Ello puede ser entendido como una concreción de la idea de que toda norma de conducta se refiere, precisamente, a un comportamiento que está "prohibido", "mandado", "permitido", etc.
} 
cometerse a través de un engaño típico ${ }^{111}$, dicho carácter no se opone -al menos desde un punto de vista teórico- al engaño omisivo, entendido como "ausencia de una afirmación verdadera debida”.

Tanto en el engaño activo como en el omisivo, la estafa conserva su carácter de delito de comunicación: en el engaño por acción el agente efectúa una comunicación (sobre hechos típicamente relevantes) mediante una afirmación mendaz; en el engaño por omisión, en cambio, no realiza una comunicación (sobre hechos típicamente relevantes) que debió y pudo llevar a cabo. En este último caso el sujeto activo es sancionado, precisamente, por no dar lugar a una comunicación que debió verificarse a través de afirmaciones verdaderas (sobre hechos típicamente relevantes) dirigidas al disponente del patrimonio ${ }^{112}$.

\section{e) El ENGAÑo CONCLUYENTE EN LA ESTAFA COMO AFIRMACión (FALSA) IMPLí́cita E INDIRECTA \\ El engaño concluyente, al igual que el engaño expreso, es una forma de engaño} activo $^{113}$, que supone la realización de una afirmación falsa sobre hechos típicamente relevantes. Lo que diferencia al primero, del segundo, dice relación con la manera en que se verifica la interacción comunicativa entre el emisor y el receptor del mensaje típicamente relevante. Mientras que en el engaño expreso la afirmación mendaz es directa ${ }^{114}$ o explícita ${ }^{115}$, en el engaño concluyente, que algunos denominan "tácito"116, la aserción del sujeto activo es indirecta ${ }^{117}$ o implícita ${ }^{118}$, es decir, se encuentra implicada en los elementos que definen la relación negocial de que se trate y sin los cuáles esta dejaría de tener sentido o perdería su razón de $\operatorname{ser}^{119}$.

El engaño activo en la estafa, en tanto acto de habla, debe comunicar un contenido típicamente relevante. El engaño expreso usualmente será llevado a cabo en forma oral o por escrito, vgr. declarando (falsamente) en un formulario que se tiene voluntad y capacidad de pagar el crédito contraído. Sin embargo, nada impide que un engaño expreso se ejecute a través de gestos ${ }^{120}$. Ello ocurrirá, por ejemplo, si el agente asiente inclinando la

${ }_{111}$ Para la discusión véase, por ejemplo, PASTOR (2004) pp. 220 y s. Véase asimismo Fernández (2005) p. 186 y Pérez del Valle (1996) pp. 379 y ss.

112 Tiedemann (2012) número marginal 22.

113 Cramer y Perron (2010) número marginal 14/15; Herrero (2000) p. 187; Maass (1982) p. 3; Naucke (1964) p. 214; Seibert (2007) p. 348, p. 355; Wessels y HillenKamp (2011) número marginal 498 en relación con número marginal 503.

114 Krack (1994) p. 87. Véase también Aldoney (2010) p. 77 y Bacigalupo (2007) p. 170.

115 Mitsch (2003) \$7, número marginal 26; WitTig (2011) \$14, número marginal 29.

116 Conde-Pumpido Ferreiro (1997) pp. 59 y ss.; Joecks (2010) \$ 263, número marginal 24; Lackner (1988) número marginal 53. Con matices STRENG (2010) pp. 18 y ss.

117 MAYer Lux (2013) pp. 198 y ss. En cambio, identifica al engaño concluyente con una manipulación de rutinas negociales Bung (2012) pp. 361 y s.

118 Arroyo de las Heras (2005) p. 23; Arzt et al. (2009) $\$ 20$, número marginal 37; Donna (2001) p. 294; YuBero (2010) p. 95.

119 De forma análoga KINDHäUser (2008) p. 585.

120 Fischer (2011) $\$ 263$, número marginal 18; KüHL (2011) $\$ 263$, número marginal 7; TiedemanN (2012) número marginal 24 en relación con número marginal 26. Con matices DUTTGE (2011) \$263, número margi- 
cabeza o indicando con su pulgar hacia arriba ante la pregunta formulada por el disponente del patrimonio. Ese gesto, que equivale a la afirmación de "sî", reemplaza a la palabra o a la escritura y asume el significado de la aserción del contenido implicado en la pregunta ${ }^{121}$. Por su parte, si el disponente pregunta: ¡este vehículo ha sido chocado?, y el agente responde moviendo la cabeza de izquierda a derecha en señal de negativa, ese gesto debe ser interpretado como la siguiente proposición: no, este vehículo no ha sido chocado.

Por su parte, el engaño concluyente usualmente será llevado a cabo a través de un determinado comportamiento, con o sin empleo de lenguaje oral o escrito, que da a entender la existencia o inexistencia de determinados hechos. En estricto rigor, el engaño no está constituido por ese comportamiento; este solo posibilita su ejecución. El engaño concluyente está constituido por una afirmación falsa sobre hechos típicamente relevantes que se encuentra implicada en la conducta desplegada por el agente. Siguiendo con el ejemplo relativo a la afirmación (falsa) de la voluntad y capacidad de pago, quien se sienta en un restaurante y pide comida o quien ingresa a un taxi e indica su lugar de destino afirma, con ello, su voluntad y capacidad de pagar por la comida o por la carrera solicitada. Resulta innecesario que lo explicite ${ }^{122}$, pues su interlocutor, atendidos los elementos propios de esa relación negocial, partirá de la base de que estos concurren, precisamente, por encontrarse implicados en su definición.

Entender al engaño activo en la estafa como comunicación de un contenido típicamente relevante no se vincula con las nociones tradicionales de lenguaje escrito, oral y gestual, por una parte, y de silencio, por la otra. La forma de expresión concreta que asuma la afirmación falsa es, para la caracterización de una aserción como expresa o concluyente, irrelevante. En ese orden de ideas, que se verifique una comunicación entre las partes no depende de si el agente en parte "habló" o en parte efectuó un determinado "movimiento corporal", sino que del significado de su comportamiento en el contexto de una determinada relación negocial. De ahí que resulte equívoco concebir al engaño concluyente como un "silencio acompañado de actos"123, idea que se plantea frecuentemente respecto de quien coloca determinados productos ante la cajera de un supermercado, afirmando, mediante ese "movimiento corporal" y pese a "no decir algo", que tiene capacidad y voluntad de pagarlos.

Resulta asimismo equívoco sostener que el engaño concluyente es una "declaración sin palabras"124. Primero, porque puede que las haya ${ }^{125}$. Segundo, porque ello dificulta innecesariamente la distinción entre acción y omisión en los delitos que, siendo teóricamente compatibles con la omisión impropia, suponen la ejecución de un acto de habla. Por el contrario, el engaño concluyente es una forma más de emisión -y no de ausencia o

\footnotetext{
nal 9; Hefendehl (2006) número marginal 78. De otra opinión Cabrera y Contreras (2009) p. 85 y MitsCH (2003) $\$ 7$, número marginal 26.

121 SCHMIDHÄUSER (1983) p. 116, número marginal 10.

122 Hernández (2012) pp. 154 y ss.

123 Definición que, por lo demás, solo provoca confusiones a la hora de distinguir entre engaño activo y engaño omisivo. De esa forma, sin embargo, NúŇ́EZ (1999) p. 225.

124 ARZT et al. (2009) \$20, número marginal 37; МrtsCh (2003) \$7, número marginal 26.

125 Tiedemann (2012) número marginal 26.
} 
de ausencia parcial- de un mensaje comunicativo ${ }^{126}$, del todo equivalente a las aserciones expresas $^{127}$.

Tanto la compatibilidad entre la conducta y la omisión, como la valoración jurídica del comportamiento omisivo en el injusto típico de que se trate, son dificultades ajenas a la noción de engaño concluyente. En efecto, siendo el engaño concluyente una forma de engaño activo, no se plantea a su respecto la necesidad de determinar el fundamento del "deber de información" y menos los casos en que este existe ${ }^{128}$. En otras palabras, al igual que en el engaño expreso, quien realiza un engaño concluyente vulnera una norma que prohíbe efectuar afirmaciones falsas sobre hechos típicamente relevantes y no una norma que manda realizar afirmaciones verdaderas sobre hechos típicamente relevantes en virtud de una posición de garante, como es propio del engaño por omisión ${ }^{129}$. Lo anterior, no solo se aplica respecto del engaño concluyente en la estafa, sino que de cualquier delito que requiera típicamente ser cometido a través de un engaño.

\section{f) El engaño CONCluyente en la estafa COMO RESUltado DE un proceso DEDUCTIVO}

El engaño concluyente en el delito de estafa supone la deducción de una afirmación falsa sobre hechos típicamente relevantes. Precisamente que deba deducirse una afirmación (falsa), provoca que el engaño concluyente sea una afirmación (falsa) indirecta, implícita o tácita, a la que se arriba mediante un razonamiento del receptor del mensaje, que no puede ser explicado recurriendo únicamente a los métodos tradicionales de interpretación ${ }^{130}$.

Un sector de la doctrina plantea que la idea de "contradicción” es característica del engaño concluyente, en el sentido de que "lo declarado (...) se ve contradicho lógica, empírica o normativamente por la ausencia de una circunstancia que, en cuanto presupuesto del sentido de la declaración, se entiende implícita en ella sin necesidad de mención expresa"131. En realidad, dicha forma de entender el engaño concluyente en el delito de estafa resulta equívoca y se vincula más bien con una noción general de aquello que es "concluyente". En la estafa, el disponente del patrimonio no realiza deducciones lógicas, empíricas o normativas ${ }^{132}$, sino que conceptuales ${ }^{133}$. Consiguientemente, si cabe hablar de

\footnotetext{
126 KINDHÄUSER (2008) pp. 588 y ss.

127 Mayer Lux (2013) pp. 201 y ss.; Rengier (2011) \$13, número marginal 8.

128 De otra forma GaUger (2001) pp. 196 y ss.; LACKNER (1988) número marginal 53; PAWLIK (1999) pp. 74 y ss., p. 97, p. 100, pp. 127 y ss.

129 Balmaceda (2012) pp. 100 y s.; Cabrera y Contreras (2009) pp. 87 y ss.; Cramer y Perron (2010) números marginales 18 y ss.; GÖsSEL (1996) \$21, número marginal 17; PIÑA (2006) pp. 83 y s.

130 Sugieren otra cosa Tiedemann (2012) número marginal 30 y TriffTERER (1971) p. 182.

131 HernándeZ (2012) p. 155. Asimismo KindHÄUsEr (2013) número marginal 110.

$132 \mathrm{Al}$ menos no realiza deducciones normativas en el sentido de concluir la vigencia de determinadas normas de conducta. Si el término es empleado para aludir a aquellos elementos jurídicos y extrajurídicos que regulan el vínculo negocial entre agente y disponente, coincidiría con la noción de engaño concluyente que aquí se plantea, pero seguirá siendo equívoco, sobre todo en atención al desarrollo de planteamientos "normativos" en materia penal que, en cuanto tales, no permiten arribar a un concepto de engaño concluyente en la estafa.

133 Para determinar la comisión de un engaño concluyente no debe realizarse una mera deducción "contextual". Primero, porque ello podría provocar un efecto similar al que acarrea recurrir a la "opinión del tráfico jurídico",
} 
una "contradicción" entre lo declarado y la ausencia de determinados hechos, esa contradicción no será ni lógica ni empírica ni normativa, sino que conceptual.

El criterio para efectuar la deducción característica del engaño concluyente en el delito de estafa son las "circunstancias que definen la relación negocial" que se verifica entre el agente y el disponente, y que la distinguen de otras relaciones negociales ${ }^{134}$. Ello permite deducir la concurrencia de aquellos hechos típicamente relevantes, cuya ausencia se oponga a aquello que caracteriza la relación negocial en la que se interviene. Para establecer qué elementos definen una relación negocial y que, consecuentemente, serán concluyentemente afirmados por quienes intervienen en ella, debe tenerse en cuenta la normativa jurídica y extrajurídica que la rige, así como ciertas implicancias comunicativas de determinados actos de habla.

Dependiendo del contexto en que se desarrolla la interacción comunicativa, el receptor e intérprete del engaño concluyente debe considerar, por ejemplo, qué es una compraventa, qué es un trabajo científico, qué es una apuesta, qué es un crédito, de acuerdo con la normativa jurídica y extrajurídica que rige esas relaciones. Así, mientras una compraventa supone, conceptualmente, la realización de determinadas prestaciones recíprocas -básicamente entregar una cosa a cambio de un precio ${ }^{135}$-, un trabajo científico implica, conceptualmente, el cumplimiento de ciertos estándares ${ }^{136}$ metodológicos vigentes en la disciplina de que se trate ${ }^{137}$, vgr. citar fuentes; que exista correspondencia entre quien dice ser el autor de la investigación y quien efectivamente la realizó; en su caso, indicar investigaciones que han tenido resultados diversos; entre otros.

Por su parte, lo propio de una apuesta y aquello que la distingue de otras relaciones negociales es "la contingencia incierta de ganancia o pérdida", idea que se opone, por ejemplo, al conocimiento del resultado de la competencia respecto de la que se apostón ${ }^{138}$,

en el sentido de constituir un concepto abierto y adaptable a toda clase de pretensiones, según cuál sea el fin que se persigue: si condenar o absolver por estafa. Segundo, porque considerar el contexto para deducir una determinada proposición en nada contribuye a la delimitación concreta del engaño concluyente. Toda conducta debe ser interpretada según el contexto comunicativo en el que se desenvuelven sus partes y ello, con independencia de si su comportamiento es activo (expreso o concluyente) u omisivo.

134 Con más o menos matices Rengier (2011) \$13, número marginal 11; WiTtig (2011) \$14, número marginal 31.

135 Para el engaño concluyente en materia de compraventa Donna (2001) p. 294; Fischer (2011) \$263, número marginal 33; Mera (1970) pp. 197 y s.

136 Hefendehl (2006) número marginal 132; KindHÄUser (2008) p. 591. Un razonamiento similar puede verse en Mañalich (2010) pp. 345 y ss., respecto de la "calidad del proceso de construcción".

137 Fundamental Jerouscheck (1999) p. 418 en relación con p. 420. Véase también Mayer Lux (2013) p. 236, con referencias ulteriores. Con todo, la mayoría de los engaños en materia de publicaciones serán expresos, atendidas las declaraciones que muchas revistas y editoriales demandan respecto del cumplimento de determinadas exigencias, entre ellas, la referencia a fuentes y la presentación de una obra llevada a cabo por quien dice ser su autor.

138 Supuesto hoy en día marginal, atendida la rapidez de las comunicaciones, la cual no da espacios para realizar apuestas respecto de competencias ya concluidas, pero cuyo término aún es desconocido para la casa de apuestas que las recibe. Con todo, a favor de un engaño concluyente en dicho caso, por ejemplo, BACIGALUPO (2007) p. 170; LACKNER (1988) número marginal 43; MERKEL (1971) p. 157, refiriéndose a la Lotería; RENGIER (2011) \$13, número marginal 12. 
así como a la manipulación del juego y de sus resultados ${ }^{139}$. La manipulación de resultados no solo contradice conceptualmente la idea de "apuesta", sino que también la de "actividad deportiva”, en la que cada competidor ha de respetar ciertas reglas de juego, por ejemplo, no utilizar sustancias proscritas para potenciar artificialmente el rendimiento de su organismo $^{140}$. Igualmente, la manipulación del proceso respectivo y de sus resultados se opone al concepto de concurso público o de subasta, los cuales, implican respetar las reglas establecidas en su llamado o en su difusión ${ }^{141}$.

Tratándose de un crédito, se postula la realización de un engaño concluyente por parte de quien, al tomarlo, afirma (implícitamente) una capacidad o voluntad de pago que, sin embargo, no tiene ${ }^{142}$. El mismo planteamiento -que, en el fondo, es una variante de la estafa de consumo-, ha sido efectuado respecto de quienes entregan cheques en pago de determinados bienes, pero careciendo de la voluntad o de la capacidad para cubrirlos ${ }^{143}$. En tales supuestos, la entrega de cheques por parte del comprador, atendida "su naturaleza de instrumentos de pago, cobrables a su sola presentación en el banco, dan a entender inequívocamente la intención y la capacidad de pago" ${ }^{144}$.

En ciertos casos, el receptor e intérprete del engaño concluyente deberá recurrir a determinadas implicancias comunicativas, relativas al sentido de determinados actos de habla, como acontece cuando el agente demanda al disponente el pago de determinadas prestaciones. En tal supuesto, el disponente del patrimonio ha de realizar el siguiente razonamiento: así como impartir una orden militar supone que quien la imparte está, por razón de su rango, facultado a darla ${ }^{145}$, quien demanda una determinada prestación lo hace porque está legitimado para ello. Consiguientemente, impartir una orden militar careciendo de facultades o demandar una prestación sin estar legitimado para ello, contradice la idea de "impartir una orden militar" y de "demandar una prestación”, respectivamente. De ahí que cometa un engaño ${ }^{146}$ concluyente, quien envía una factura para el pago de trabajos no

\footnotetext{
139 BGHSt 29, p. 165 , pp. 167 y ss.; BGHSt 51, p. 165, pp. 171 y ss.; GaEde (2007) p. 16; GÖsSEL (1996) § 21, número marginal 38; LeSCH (2003) p. 345; VALERIUS (2005) p. 92.

140 Así, la primera acepción del término "dopar” contenida en el Diccionario de la RAE. Para el engaño concluyente por empleo de sustancias prohibidas véase CHerkeh y MOMSEn (2001) p. 1748; Grotz (2005) pp. 94 y ss.; Отто (1994) p. 15.

141 BGHSt 47, p. 83, pp. 86 y s. Véase igualmente DutTge (2011) \$263, número marginal 14; FISCHER (2011) \$ 263, número marginal 22; KindHÄUSER (2008) p. 591; STRENG (2010) pp. 19 y s.

142 Mayer Lux (2013) pp. 224 y s. Véase también Vives Antón y GonZÁlez Cussac (2010) pp. 437 y s., con referencias sobre la jurisprudencia del Tribunal Supremo español. Restrictivo Contreras (1992) p. 164.

143 Hefendehl (2006) número marginal 122; KüHL (2011) \$263, número marginal 11; ОтTO (2005) \$51, número marginal 16; Wessels y HillenkAmp (2011) número marginal 498. Véase también MaYer Lux (2010) pp. 73 y ss., comentando la Sentencia del Segundo Tribunal de Juicio Oral en lo Penal de Santiago de 29 de abril de 2009 (ROL: 36-2009).

144 Aldoney (2010) p. 79. Dichos casos demuestran, que la importancia de la estafa de consumo en restaurantes, hoteles, etc., más que en su aplicación práctica -exigua, atendida la escasa significación de muchos de sus supuestos- radica en las ideas que a partir de ella pueden desarrollarse para la delimitación del engaño típico en otras situaciones.

145 KindHÄUser (2013) número marginal 116; Williams (2004) p. 77.

146 Bung (2012) p. 359.
} 
realizados ${ }^{147}$ o por un monto superior al que corresponde ${ }^{148}$ de acuerdo con las normas (jurídicas) que rigen la relación negocial en cuestión.

En cambio, no se comete un engaño concluyente por el simple hecho de cobrar un precio superior al de mercado. En una economía de libre mercado, como la nuestra, el precio de los bienes y servicios es fijado, normalmente, de acuerdo con la oferta y la demanda de la que son objeto ${ }^{149}$. Consiguientemente y en términos generales, no es posible efectuar una afirmación "falsa" respecto de la conveniencia económica del precio establecido por el vendedor $^{150}$ o de la correspondencia entre este y aquel que usualmente cobran otros oferentes ${ }^{151}$.

\section{EL ENGAÑO CONCLUYENTE EN LAS NORMAS CHILENAS RELATIVAS AL DELITO DE ESTAFA}

Para nadie constituye un misterio que la dogmática chilena en materia de estafa ha tenido que efectuar importantes esfuerzos a fin de interpretar el complejo entramado de normas relativo a dicho tipo delictivo. La ausencia de una disposición genérica ${ }^{152}$ que esté en sintonía con las directrices fundamentales de una adecuada técnica legislativa y sea respetuosa del principio de taxatividad, ha provocado una separación entre lo que literalmente establecen las disposiciones del Código penal chileno y el desarrollo doctrinal de los elementos del delito de estafa. Dicho divorcio no es en sí mismo un problema, en la medida en que permita sostener una coherencia material entre lo que establece la ley y lo que la doctrina elabora a partir de esas disposiciones.

Sabido es que el Código Penal chileno hace referencias explícitas al engaño y al perjuicio patrimonial en las normas que regulan el tipo penal de estafa ${ }^{153}$. Las dificultades surgen respecto del error y, sobre todo, de la disposición patrimonial que le sigue, toda vez que el primero, a diferencia de la segunda, puede ser concebido como la contrapartida del engaño del agente ${ }^{154}$-que sí se consagra-, esto es, como sinónimo de "ser engañado" 155.

Pese a las dudas que puede despertar la consagración del error y de la disposición patrimonial como elementos del tipo de estafa, ellos son tan constitutivos de dicho delito como el engaño y el perjuicio ${ }^{156}$. Más aún, el error y la disposición patrimonial permiten calificar a la estafa como un delito de "comunicación” y de "autolesión", darle una fisiono-

\footnotetext{
147 Cramer y Perron (2010) número marginal 16c; KüHl (2011) \$263, número marginal 9; RengIer (2011) $\$ 13$, número marginal 11 .

148 BGH, NStZ 2009, p. 507.

149 Hefendehl (2006) número marginal 128; KindHÄUser (2013) número marginal 130; KreY et al. (2012) número marginal 506; KÜHNE (1978) p. 66.

150 FisCHER $(2011) \$ 263$, número marginal 36; GÖSSEL (1996) $\$ 21$, número marginal 35; KRAATZ (2011) p. 282; Tiedemann (2012) número marginal 35.

151 Отто (2005) \$ 51, número marginal 17; W ITTIG (2011) \$14, número marginal 35a.

152 Balmaceda (2011) p. 63.

153 Fernández (2005) p. 183; Matus (2012) p. 328.

154 Cabrera y Contreras (2009) pp. 32 y ss.

155 Ellmer (1986) pp. 128 y ss.; Matus (2012) p. 328; Yubero (2010) p. 43, 45.

156 Etcheberry (2010) p. 392; Politoff et al. (2005) p. 418; Schlack (2008) p. 262; también Garrido Montt (2011) p. 346; Piña (2006) pp. 46 y ss.; VArgas (2010) p. 56. Respecto de la legislación comparada
} 
mía propia y distinguirla de las restantes figuras típicas de la Parte Especial ${ }^{157}$. En este orden de ideas, si se prescindiera del error y de la disposición patrimonial en la estructura del delito de estafa, la existencia de dicha figura delictiva perdería parte importante de su sentido. Primero, ante delitos patrimoniales de heterolesión, vgr. el hurto ${ }^{158}$. Segundo, frente a figuras que contienen descripciones en que hay falsedad o engaño, por una parte, y perjuicio patrimonial, por la otra, como acontece en diversos fraudes diseminados a lo largo del Código Penal o de leyes especiales.

El engaño, elemento claramente consagrado en las normas penales chilenas sobre el delito de estafa, debe ser entendido, genéricamente, como una afirmación falsa sobre hechos típicamente relevantes. Que esa aserción falsa vaya acompañada de una puesta en escena del sujeto activo no determina la calificación de esa conducta como engaño típico. De esta forma, puede que el agente se valga de una mise en scène para ejecutar la conducta, pero que no lo haga, no excluye la existencia de un engaño típico para efectos de la estafa, ni siquiera tratándose de los engaños "calificados" del artículo 468 del Código Penal ${ }^{159}$.

Todas las hipótesis de estafa contempladas en el Código Penal chileno pueden ser llevadas a cabo a través de un engaño (activo) expreso o concluyente. Las limitaciones que plantean las normas penales chilenas no dicen relación con la forma que puede revestir el engaño típico, sino que con los hechos a los cuales este puede referirse. Por lo mismo, la figura específica de estafa que se aplique dependerá del hecho al que se refiera el engaño y no de la forma que asuma la aserción falsa en cuestión.

Se ha insistido en que el objeto del engaño en la estafa es un hecho típicamente relevante y que su definición dependerá de la relación negocial concreta que se verifique entre el sujeto activo y el disponente del patrimonio. Con todo, existen disposiciones que establecen hechos específicos a los que ha de referirse el engaño, los cuales deben ser considerados como típicamente relevantes por expresa disposición legal. Por ejemplo: el artículo 467, en que el engaño típico ${ }^{160}$ debe tener por objeto la "sustancia, cantidad o calidad de las cosas" que se entregan en virtud de un título obligatorio; el artículo 469 números 1, 2 y 5 , en que el engaño debe referirse a la "calidad, ley o peso" o a los "pesos o medidas" de determinados objetos, o bien, a "supuestas remuneraciones a empleados públicos", respectivamente. Lo mismo acontece con el engaño típico del artículo 470 número 7 , que debe tener por objeto la manipulación del juego de que se trate "para asegurar la suerte".

El engaño del artículo 468, por su parte, puede referirse a usar nombre fingido; a atribuirse poder, influencia o créditos supuestos; a aparentar bienes, créditos, comisión, empresa o negociación imaginarios; o bien, consistir en cualquier afirmación falsa "semejante” a las indicadas en dicha norma. La aserción falsa será “semejante” a las aludidas, si

véase Damianovich (1988) pp. 242 y s.; de otra opinión con respecto a la función que desempeña el error en el delito de estafa Gómez Benítez (1985) pp. 333 y ss.

157 FERNÁNDEZ (2005) p. 183.

158 Hernández (2003) p. 168. Véase también ArzT et al. (2009) \$20, número marginal 28.

159 Cabrera y Contreras (2009) p. 19. De otra opinión Bullemore y Mackinnon (2005) pp. 130 y ss.; ETCHeberry (2010) pp. 406 y ss.; Politoff et al. (2005) pp. 443 y ss.

160 Disposición que, a juicio de Mera (2005) pp. 178 y ss., no solo contempla casos de estafa. Califica esta figura como un supuesto especial de estafa, en cambio, Fernández (2005) p. 183. 
se refiere a un hecho análogo a los establecidos en el artículo 468, con independencia de la forma concreta que asuma la afirmación falsa (sobre hechos típicamente relevantes) constitutiva de engaño ${ }^{161}$. De esta manera, las conductas descritas en el artículo 468 pueden implicar una mise en scène, pero que esta no concurra no excluye la realización de un engaño típico. Usar nombre fingido, atribuirse poder o aparentar bienes puede llevarse a cabo perfectamente mediante una afirmación falsa que no vaya acompañada de apariencia externa $\operatorname{alguna}^{162}$.

Finalmente, debe mencionarse la estafa del artículo 473, en que la disposición patrimonial perjudicial determinada por error puede ser producto de "cualquier engaño que no se halle expresado en los artículos anteriores". Esta clase de estafa, que cierta doctrina califica de figura "básica"163 o denomina estafa "residual"164 - en oposición a las estafas calificadas o agravadas del artículo 468-, es "básica" o "residual” en atención al objeto de referencia de la afirmación falsa y no de la forma concreta que asuma la aserción mendaz. El legislador nacional ha consagrado estafas "calificadas", indicando en la descripción típica los hechos cuya afirmación falsa considera particularmente grave, en oposición a la figura "residual", que puede referirse a cualquier otro hecho, con una limitación: ha de tratarse de hechos típicamente relevantes, según la específica relación negocial que se verifique entre el agente y el disponente del patrimonio.

\section{BIBLIOGRAFÍA}

Adam, Leonhard (1927): “Die Lüge im Recht”, en Lipmann, Otto y Plaut, Paul (edits.), Die Lüge in psychologischer, philosophischer, juristischer, pädagogischer, historischer, soziologischer, sprach- und literaturwissenschaftlicher und entwicklungsgeschichtlicher Betrachtung (Leipzig, Johann Ambrosius Barth) pp. 158-186.

Aguilar, Cristian (2008): Delitos patrimoniales (Santiago, Editorial Metropolitana).

Aldoney, Rodrigo (2010): "Comentario a la STOP de 16 de mayo de 2007 (RUC: 05006347489) y a la STOP de 26 de junio de 2007 (RUC: 06008931478)”, Doctrina y Jurisprudencia Penal, $\mathrm{N}^{\circ}$ 1: pp. 7380.

Antón Oneca, José (1958): “Estafas”, en Mascareñas, Carlos E. (dir.), Nueva Enciclopedia Jurídica (Barcelona, Editorial Francisco Seix) Tomo IX, pp. 56-90.

\footnotetext{
161 Politoff et al. (2005) p. 444, entienden, que los rangos más altos de penalidad, en comparación con la figura del artículo 473, se fundamentan en la forma que ha de asumir el engaño, el cual supondrá un ardid o puesta en escena. Sin embargo, en la p. 445 de la obra aludida, sostienen que las "[h]ipótesis semejantes que se pueden aparentar son: edad, título, cualidades personales, etc.”, acercándose con ello a lo que aquí se plantea: que la semejanza entre un engaño y otro tiene que ver con su objeto de referencia (edad, título, cualidades personales, etc.) y no con la forma que asuma.

162 De otra opinión Mera (2005) pp. 258 y ss.

163 Cabrera y Contreras (2009) p. 16; Politoff et al. (2005) pp. 416 y ss. De otra opinión Etcheberry (2010) p. 408; Fernández (2005) p. 183; Garrido Montt (2011) pp. 345 y s.; Piña (2010) p. 45, aunque incluyendo en el tipo básico tanto al artículo 473 como al 468.

164 En el mismo sentido Labatut (2012) p. 226; Yubero (2010) pp. 104 y s., quien alude a estafa "subsidiaria" y "complementaria".
} 
Arroyo de las Heras, Alfonso (2005): Los delitos de estafa y falsedad documental (Barcelona, Bosch).

Arzt, Gunther; Weber, Ulrich; Heinrich, Bernd y Hilgendorf, Eric (2009): Strafrecht Besonderer Teil (2a ed., Bielefeld, Gieseking).

Bacigalupo, Enrique (2007): Falsedad documental, estafa y administración desleal (Madrid, Marcial Pons).

Bajo Fernández, Miguel (1987): Manual de Derecho Penal. Parte Especial (Delitos Patrimoniales y Económicos) (Madrid, Centro de Estudios Ramón Areces).

Balmaceda, Gustavo (2012): El delito de estafa (Santiago, LegalPublishing) 510 pp.

Balmaceda, Gustavo (2011): "El delito de estafa en la jurisprudencia chilena", Revista de Derecho (Valdivia), vol. 24 No 1: pp. 59-85.

Balmaceda, Gustavo (2010): “El 'engaño' en el delito de estafa”, Doctrina y Jurisprudencia Penal, N 1: pp. 328.

Balmaceda, Gustavo y Araya, Ignacio (2010): "Engaño en la estafa: ¿Una puesta en escena?", Revista de Estudios de la Justicia, N 12: pp. 351380.

Becker, Walter Gustav (1948): Der Tatbestand der Lüge. Ein Beitrag zur Abstimmung von Recht und Ethik (Tübingen, Mohr Siebeck).

Binding, Karl (1902): Lehrbuch des Gemeinen Deutschen Strafrechts. Besonderer Teil (2a ed., Leipzig, Wilhelm Engelmann) Tomo I.

Bockelmann, Paul (1982): Strafrecht Besonderer Teil/1 (2a ed., München, Beck) 188 pp.

BunG, Jochen (2007): “Gefährdungsschaden und Vermögensverlust”, en: InsTITUT FÜR KRIminalwissenschaften und Rechtsphilosophie Frankfurt am Main (edit.), Jenseits des rechtsstaatlichen Strafrechts (Frankfurt am Main, Peter Lang) pp. 363-377.

Bung, Jochen (2012): "Konkludente Täuschung? Von der fehlenden zur Fehlvorstellung beim Betrug”, Goltdammer's Archiv für Strafrecht (GA): pp. 354-363.

Bullemore, Vivian y Mackinnon, John (2005): Curso de Derecho Penal. Parte Especial (Santiago, LexisNexis) Tomo III.

Bustos, Juan (2009): Derecho Penal. Parte Especial (2a ed., actualizada por Gustavo BALMACeda y Carlos Castro, Santiago, Ediciones Jurídicas de Santiago) Tomo III.

CABrera, Jorge y Contreras, Marcos (2009): El engaño típicamente relevante a título de estafa (Santiago, LegalPublishing).

Calle Rodríguez, María Victoria (1998): Falsedades documentales no punibles (Madrid, Editoriales de Derecho Reunidas).

Carrara, Francesco (1959): Programa de Derecho Criminal. Parte Especial (trad. José Ortega y Jorge Guerrero, Bogotá, Temis) Vol. IV.

Cherkeh, Rainer T. y Momsen, Carsten (2001): “Doping als Wettbewerbsverzerrung?”, Neue Juristische Wochenschrift (NJW): pp. 1745-1752.

Choclán Montalvo, José Antonio (2000): El delito de estafa (Barcelona, Bosch) 397 pp.

Ciano, Ariel (2006): Defraudaciones. Análisis de fraudes usuales: Estafa procesal; fraudes por emisión ilegal de cheques; estafa con automotores (Buenos Aires, Hammurabi).

Conde-Pumpido Ferreiro, Cándido (1997): Estafas (Valencia, Tirant lo Blanch).

Contreras, Raúl (1992): El delito de estafa (Santiago, ConoSur). 
Cramer, Peter y Perron, Walter (2010): “\$263”, en: Schönke/Schröder. Strafgesetzbuch. Kommentar (28a ed., München, Beck).

Creus, Carlos (1999): Derecho Penal. Parte Especial (reimp. de la 6a ed., Buenos Aires, Astrea) Tomo I.

Damianovich, Laura (1988): Delitos contra la propiedad (2a ed., Buenos Aires, Editorial Universidad).

Davidson, Donald (2009): Inquiries into Truth and Interpretation (reimp. de la 2a ed., Oxford, Clarendon Press).

Davidson, Donald (2004): Problems of Rationality (Oxford, Clarendon Press) 280 pp.

Dayenoff, David (2003): Derecho Penal. Parte Especial (Buenos Aires, Editorial García Alonso).

Díez-Picazo, Luis (1979): Fundamentos del Derecho Civil Patrimonial (2a reimp. de la $1^{\text {a }}$ ed., Madrid, Tecnos) Vol. I.

Donna, Edgardo (2001): Derecho Penal. Parte Especial (Buenos Aires, RubinzalCulzoni) Tomo IIB.

Duttge, Gunnar (2011): “\$\$ 263-266 b”, en Dölling, Dieter; Duttge, Gunnar y RÖsSNer, Dieter (edits.), Gesamtes Strafrecht. StGB. StPO. Nebengesetze. Handkommen$\operatorname{tar}\left(2^{\mathrm{a}}\right.$ ed., Baden-Baden, Nomos).

Ellmer, Manfred (1986): Betrug und Opfermitverantwortung (Berlin, Duncker \& Humblot).

Etcheberry, Alfredo (2010): Derecho Penal. Parte Especial (reimp. de la $3^{a}$ ed., Santiago, Editorial Jurídica de Chile) Tomo III.

FALKenberG, Gabriel (1982): Lügen. Grundzüge einer Theorie sprachlicher Täuschung (Tübingen, Niemeyer).

FAnelli, Andrea (2009): La truffa (2a ed., Milano, Giuffrè).

FERnÁndeZ, Álvaro (2005): "Engaño y víctima en la estafa", Revista de Derecho de la Pontificia Universidad Católica de Valparaíso, vol. 26 No 1: pp. 181-193.

Fernandes Godinho, Inês y Mayer Lux, Laura (2011): "A burla como crime contra o património: superação de uma tautologia", Revista Portuguesa de Ciência Criminal, $\mathrm{N}^{\circ} 2$ : pp. 237-266.

FInZI, Conrado A. (1961): La estafa y otros fraudes (Buenos Aires, Depalma).

FISCHER, Thomas (2011): Strafgesetzbuch und Nebengesetze (58a ed., München, Beck).

Flume, Werner (1979): Allgemeiner Teil des Bürgerlichen Rechts (3a ed., Berlin, Springer) Tomo II.

Fontán Balestra, Carlos (2002): Derecho Penal. Parte Especial (16 a ed., actualizada por Guillermo Ledesma, Buenos Aires, AbeledoPerrot).

Frisch, Wolfgang (1979): "Funktion und Inhalt des 'Irrtums' im Betrugstatbestand", en Kaufmann, Arthur; Bemmann, Günter; Krauss, Detlef y Volk, Klaus (edits.), Festschrift für Paul Bockelmann zum 70. Geburtstag (München, Beck) pp. 647-667.

FrISCH, Wolfgang (2008): "Grundfragen der Täuschung und des Irrtums beim Betrug. Zum so genannten Recht auf Wahrheit”, en PUTZKE, Holm et al. (edits.), Strafrecht zwischen System und Telos. Festschrift für Rolf Dietrich Herzberg zum siebzigsten Geburtstag (Tübingen, Mohr Siebeck) pp. 729-762. 
Frisch, Wolfgang (2007): "Konkludentes Täuschen. Zur Normativität, Gesellschaftsbezogenheit und theoretischen Fundierung eines Begriffs", en PAWLIK, Michael y ZACZYK, Rainer (edits.), Festschrift für Günther Jakobs zum 70. Geburtstag (Köln, Carl Heymanns Verlag) pp. 97-130.

Gaede, Karsten (2011): “\$\$ 263266b”, en LeIPold, Klaus; TsambiKaKis, Michael y Zöller, Mark A. (edits.), Anwaltkommentar StGB (Bonn, Deutscher Anwaltverlag).

Gaede, Karsten (2007): "Betrug durch den Abschluss manipulierter Fußballwetten: Das HoyzerUrteil als Sündenfall der Ausdehnung des Betrugstatbestandes?”, Onlinezeitschrift für Höchstrichterliche Rechtsprechung im Strafrecht (HRRS): pp. 1620. Disponible en: http://www.hrr-strafrecht.de/hrr/archiv/07-01/hrrs-1-07.pdf [fecha de consulta: 10 de septiembre de 2013].

Gallego Soler, José Ignacio (2005): "Fundamento y límites de los deberes de autoprotección de la víctima en la estafa", Anuario de Derecho Penal y Ciencias Penales (ADPCP), No LVIII: pp. 529-559.

García Cavero, Percy (2010): Nuevas formas de aparición de la criminalidad patrimonial (Lima, Jurista Editores).

GARCía RIVAS, Nicolás (2005): "Estructura jurisprudencial del delito de estafa (una revisión crítica de sus elementos objetivos)", en Borx Reig, Javier (dir.), Estafas y falsedades (Análisis jurisprudencial) (Madrid, Iustel) pp. 19-46.

Garrido Montt, Mario (2011): Derecho Penal. Parte Especial (reimp. de la 4a ed., Santiago, Editorial Jurídica de Chile) Tomo IV.

Gauger, Michael (2001): Die Dogmatik der konkludenten Täuschung (Frankfurt am Main, Peter Lang).

GiEsE, Bettina (1992): Untersuchungen zur sprachlichen Täuschung (Tübingen, Niemeyer).

Gómez Benítez, José Manuel (1985): "Función y contenido del error en el tipo penal de estafa”, Anuario de Derecho Penal y Ciencias Penales (ADPCP), No XXXVIII: pp. 333-345.

GonZÁlez Rus, Juan José (2011): "Delitos contra el patrimonio y contra el orden socioeconómico (V). Las defraudaciones. La estafa”, en Morillas Cueva, Lorenzo (coord.), Sistema de Derecho Penal Español. Parte Especial (Madrid, Dykinson) pp. 481-511.

Gössel, Karl Heinz (1996): Strafrecht Besonderer Teil (Heidelberg, C. F. Müller) Tomo 2.

Grewendorf, Günther (1982): "Behaupten und Zustimmen”, en Gethmann, Carl-Friedrich (edit.), Logik und Pragmatik (Frankfurt am Main, Suhrkamp) pp. 125-142.

Grima Lizandra, Vicente (2005): "La conducta típica del delito de estafa: reflexiones a la luz de la jurisprudencia”, en Borx Reig, Javier (dir.), Estafas y falsedades (Análisis jurisprudencial) (Madrid, Iustel) pp. 47-66.

Grisolía, Francisco (1997): "La estafa procesal en el derecho penal chileno", Revista Chilena de Derecho, vol. 24 No 3: pp. 417-422.

Grotz, Stefan (2005): "Zur Betrugsstrafbarkeit des gesponsorten und gedopten Sportlers", Zeitschrift für Sport und Recht (SpuRt): pp. 93-97.

GrÜNwald, Gerald (1966): “Der Vorsatz des Unterlassungsdelikts”, en: GeERds, Friedrich y NAUCKE, Wolfgang (edits.), Beiträge zur gesamten Strafrechtswissenschaft. Festschrift für Hellmuth Mayer zum 70. Geburtstag (Berlin, Duncker \& Humblot) pp. 281-303. 
Gutiérrez Francés, Mariluz (2010): "Resultado típico en la estafa: La disposición patrimonial lesiva", Doctrina y Jurisprudencia Penal, No 2: pp. 3-34.

Habermas, Jürgen (1995): Theorie des kommunikativen Handelns (Frankfurt am Main, Suhrkamp) Tomo I.

Hefendehl, Roland (2006): “\$\$ 263-266 b”, en Joecks, Wolfgang y Miebach, Klaus (edits.), Münchener Kommentar. Strafgesetzbuch (München, Beck) Tomo 4.

Hernández, Héctor (2003): "Aproximación a la problemática de la estafa”, en: Cury, Enrique et al., Problemas Actuales de Derecho Penal (Temuco, Universidad Católica de Temuco) pp. 147-190.

Hernández, Héctor (2012): "La punibilidad de la colusión (secreta) de precios en el derecho chileno", Política Criminal, vol. 7 N 13: pp. 147-167. Disponible en: http://www. politicacriminal.cl/Vol_07/n_13/Vol7N13A4.pdf [fecha de consulta: 10 de septiembre de 2013].

Hernández, Héctor (2010 a): "Normativización del engaño y nivel de protección de la víctima en la estafa: lo que dice y no dice la dogmática", Revista Chilena de Derecho, vol. 37 No 1: pp. 9-41.

Hernández, Héctor (2010 b): "Por qué no puede prescindirse de la exigencia de error en la estafa", Doctrina y Jurisprudencia Penal, $\mathrm{N}^{\circ}$ 1: pp. 29-41.

Herrero, César (2000): Infracciones penales patrimoniales (Madrid, Dykinson) 359 pp.

HruschKa, Joachim (2002): "La conducta de la víctima como clave para un sistema de los delitos patrimoniales que llevan consigo sustracción”, Anuario de Derecho Penal y Ciencias Penales (ADPCP), No LII: pp. 451-466.

HruschKa, Joachim (1988): Strafrecht nach logisch-analytischer Methode (2a ed., Berlin, Walter de Gruyter).

Hungerland, Isabel (1979): “Kontext-Implikation”, en Meggle, Georg (edit.): Handlung, Kommunikation, Bedeutung (Frankfurt am Main, Suhrkamp) pp. 266-326.

Jerouscheck, Günter (1999): "Strafrechtliche Aspekte des Wissenschaftsbetruges", Goltdammer's Archiv für Strafrecht (GA): pp. 416-442.

Jiménez de AsúA, Luis (2005): Crónica del Crimen (7a ed., Buenos Aires, LexisNexis).

JoECKs, Wolfgang (2010): Studienkommentar StGB (9a ed., München, Beck).

KARGL, Walter (2007): "Die Bedeutung der Entsprechungsklausel beim Betrug durch Schweigen”, Zeitschrift für die gesamte Strafrechtswissenschaft (ZStW), Vol. 119: pp. 250-289.

Kasiske, Peter (2009): "Die konkludente Täuschung bei $\$ 263$ StGB zwischen Informationsrisiko und Informationsherrschaft", Goltdammer's Archiv für Strafrecht (GA): pp. 360-370.

Kern, Eduard (1919): Die Äußerungsdelikte (Tübingen, Mohr Siebeck) 97 pp.

Kindhäuser, Urs (2013): “\$263”, en: Kindhäuser, Urs; Neumann, Ulfrid y Paeffgen, HansUllrich (edits.), Nomos Kommentar. Strafgesetzbuch (4a ed., BadenBaden, Nomos) Tomo III.

Kindhäuser, Urs (2008): “Konkludentes Täuschen”, en: Sieber, Ulrich; Dannecker, Gerhard; KindhäUser, Urs; Vogel, Joachim y Walter, Tonio (edits.), Strafrecht und Wirtschaftsstrafrecht. Festschrift für Klaus Tiedemann zum 70. Geburtstag (Köln, Carl Heymanns Verlag) pp. 579-593. 
KraATZ, Erik (2011): "Individualisierung contra Normativierung. Oder: Überlegungen zum Auslegungsmaßstab konkludenter Täuschungshandlungen beim Betrug ( $\$ 263$ StGB)", en: Geisler, Claudius; Krattz, Erik; Kretschmer, Joachim; Schneider, Hartmut y SOWADA, Christoph (edits.), Festschrift für Klaus Geppert zum 70. Geburtstag (Berlin, Walter de Gruyter) pp. 269-285.

KraCK, Ralf (1994): List als Straftatbestandsmerkmal (Frankfurt am Main, Peter Lang).

Krey, Volker; Hellmann, Uwe y Heinrich, Manfred (2012): Strafrecht Besonderer Teil (16a ed., Stuttgart, Kohlhammer) Tomo 2.

KüHL, Kristian (2011): Lackner/Kühl. Strafgesetzbuch. Kommentar (27a ed., München, Beck). KüHne, Hans Heiner (1978): Geschäftstüchtigkeit oder Betrug? (Kehl am Rhein, N. P. Engel).

Labatut, Gustavo (2012): Derecho Penal (reimp. de la $7^{\text {a }}$ ed., actualizada por el profesor Julio Zenteno, Santiago, Editorial Jurídica de Chile) Tomo II.

Lackner, Karl (1988): “\$263”, en: Jescheck, Hans-Heinrich; Russ, Wolfgang y Willms, Günther (edits.), Leipziger Kommentar. Strafgesetzbuch. Großkommentar (10a ed., Berlin, Walter de Gruyter) Tomo 6.

Laporta, Mario (2013): Delito Fiscal (Montevideo - Buenos Aires, B de f).

Larenz, Karl y Wolf, Manfred (2004): Allgemeiner Teil des Bürgerlichen Rechts (9a ed., München, Beck).

LeÓn Hurtado, Avelino (1991): La voluntad y la capacidad en los actos jurídicos (4a ed., Santiago, Editorial Jurídica de Chile).

Lesch, Heiko (2003): “Anmerkung zu BGH, Urteil vom 28.11.2002 - 4 StR 260/02”, Juristische Rundschau (JR): pp. 344346.

MaAss, Wolfgang (1982): Betrug verübt durch Schweigen (Gießen, Brühlscher Verlag).

Mañalich, Juan Pablo (2010): “¿Responsabilidad jurídico-penal por causaciones de menoscabo patrimonial a propósito de fallas en la construcción de inmuebles?”, Política Criminal, vol. $5 \mathrm{~N}^{\circ}$ 10: pp. 341351. Disponible en: http://www.politicacriminal.cl/ Vol_05/n_10/Vol5N10A2.pdf [fecha de consulta: 10 de septiembre de 2013].

MATUS, Jean Pierre (2013): “De nuevo sobre la falta de punibilidad de los atentados contra la libre competencia, de conformidad con el Art. 285 del Código penal. Algunos aspectos de la discusión con Héctor Hernández en Política Criminal', Política Criminal, vol. $8 \mathrm{~N}^{\circ}$ 15: pp. 314362. Disponible en: http://www.politicacriminal.cl/Vol_08/n_15/ Vol8N15D1.pdf [fecha de consulta: 10 de septiembre de 2013].

Matus, Jean Pierre (2012): "Acerca de la actual falta de punibilidad en Chile de los acuerdos de precios", Política Criminal, vol. 7 No 14: pp. 318-356. Disponible en: http:// www.politicacriminal.cl/Vol_07/n_14/Vol7N14A3.pdf [fecha de consulta: 10 de septiembre de 2013].

Maurach, Reinhart; Schroeder, Friedrich-Christian y Maiwald, Manfred (2009): Strafrecht Besonderer Teil (10ª ed., Heidelberg, C. F. Müller) Tomo 1.

MaYer, Hellmuth (1953): Strafrecht Allgemeiner Teil (Stuttgart, Kohlhammer).

Mayer Lux, Laura (2010): "Comentario de la STOP de Santiago de 29 de abril de 2009 (ROL: 36-2009)”, Doctrina y Jurisprudencia Penal, No 2: pp. 73-85.

Mayer Lux, Laura (2013): Die konkludente Täuschung beim Betrug (Göttingen, V\&R unipress - Bonn University Press). 
Mera, Jorge (2005): Fraude civil y penal. El delito de entrega fraudulenta (reimp. de la $3^{a}$ ed., Santiago, LegalPublishing).

Mera, Jorge (1970): "Nota a sentencia. Corte Santiago: Estafa", Revista de Ciencias Penales, Tomo XXIX No 2: pp. 196-199.

Mera, Jorge (1969): "Relaciones entre los delitos de entrega fraudulenta y de estafa", Revista de Ciencias Penales, Tomo XXVIII No 3: pp. 185-209.

Merkel, Adolf (1971): "Die Lehre vom strafbaren Betruge", en: El MISMO, Kriminalistische Abhandlungen (reimp. de la ed. de Leipzig de 1867, Detlev Auverman, Glashütten im Taunus) Tomo II.

Mestre, Esteban (2011): "Delitos contra el patrimonio y contra el orden socioeconómico", en: Lamarca, Carmen (coord.), Derecho Penal. Parte Especial (6a ed., Madrid, Colex) pp. 255-422.

Miтsch, Wolfgang (2003): Strafrecht Besonderer Teil 2. Vermögensdelikte (Kernbereich) (2a ed., Berlin, Springer) Tomo 1.

Müller, Bernd (1981): "Betrug durch Geltendmachung von Ehemaklerlohn? - OLG Stuttgart, NJW 1979, 2573”, Juristische Schulung (JuS): pp. 255-259.

Muñoz Conde, Francisco (2010): Derecho Penal. Parte Especial (18 a ed., Valencia, Tirant lo Blanch).

Muñoz Cuesta, Javier (2003): "Engaño bastante en el delito de estafa: El solo uso de tarjeta de crédito sustraída por quien no es su titular no motiva el delito de estafa", Repertorio de Jurisprudencia Aranzadi, No 7: pp. 279-281.

Naucke, Wolfgang (1964): Zur Lehre vom strafbaren Betrug (Berlin, Duncker \& Humblot).

Núnez, Ricardo (1999): Manual de Derecho Penal. Parte Especial (2a ed., actualizada por Víctor Reinaldi, Córdoba, Marcos Lerner).

Oliver, Guillermo (2013): Delitos contra la propiedad (Santiago, LegalPublishing).

Ossandón Widow, María Magdalena (2010): "Comentario a la SCS de 19 de agosto de 2005 (ROL: 519-03)”, Doctrina y Jurisprudencia Penal, N 1: pp. 81-90.

Отто, Harro (2005): Grundkurs Strafrecht. Die einzelnen Delikte (7a ed., Berlin, Walter de Gruyter).

Отто, Harro (1994): “Zur Strafbarkeit des Doping - Sportler als Täter und Opfer”, Zeitschrift für Sport und Recht (SpuRt): pp. 10-16.

Ovalle Madrid, Germán (2010): "Comentario a la SCA Temuco de 30 de junio de 2008 (ROL: 4-2008)”, Doctrina y Jurisprudencia Penal, N 1: pp. 91-100.

PAstor, Nuria (2010): "Consideraciones sobre la delimitación del engaño típico en el delito de estafa", Doctrina y Jurisprudencia Penal, N 1: pp. 43-63.

Pastor, Nuria (2004): La determinación del engaño típico en el delito de estafa (Madrid, Marcial Pons).

PAWLiK, Michael (1999): Das unerlaubte Verhalten beim Betrug (Köln, Carl Heymanns Verlag).

Pérez del Valle, Carlos (1996): "El engaño omisivo en la estafa”, Cuadernos de Política Criminal, No 59: pp. 373-399.

Pérez Manzano, Mercedes (1995): "Acerca de la imputación objetiva de la estafa”, Hacia un derecho penal económico europeo. Jornadas en honor del profesor Klaus Tiedemann (Madrid, Boletín Oficial del Estado) pp. 285-309. 
PIÑA, Juan Ignacio (2010): "Comentario a la SCA de 20 de marzo de 2007 (ROL: 2482007)", Doctrina y Jurisprudencia Penal, N 1: pp. 101-107.

PiÑA, Juan Ignacio (2006): Fraude de Seguros (2a ed., Santiago, Editorial Jurídica de Chile). Politoff, Sergio; Matus, Jean Pierre y Ramírez, María Cecilia (2005): Lecciones de Derecho Penal Chileno. Parte Especial (reimp. de la 2a ed., Santiago, Editorial Jurídica de Chile). Puppe, Ingeborg (2008): Kleine Schule des juristischen Denkens (Göttingen, Vandenhoeck \& Ruprecht).

PupPE, Ingeborg (1991): "Wie wird man Mittäter durch konkludentes Verhalten?”, Neue Zeitschrift für Strafrecht (NStZ): pp. 571-574.

Queralt, Joan (2010): Derecho Penal Español. Parte Especial (6a ed., Barcelona, Atelier).

Quintero Olivares, Gonzalo (2011): "Delitos contra el patrimonio y contra el orden socioeconómico” en Quintero Olivares, Gonzalo (dir.), Comentarios a la Parte Especial del Derecho Penal (9a ed., Navarra, Aranzadi) pp. 613-806.

Rebollo, Rafael (2008): "Propuestas para la controversia en la delimitación típica del delito de estafa: la distinción con el fraude civil y la reinterpretación del engaño", Revista de Derecho y Proceso Penal, No 19: pp. 93-118.

Rengier, Rudolf (2011): Strafrecht Besonderer Teil I. Vermögensdelikte (13a ed., München, Beck).

RiCHTER, Alarich (2005): “Mündliche, schriftliche und wahre Gründe’ - eine Linguistik der Lüge im Recht”, en Depenheuer, Otto (edit.), Recht und Lüge (Münster, Lit) pp. 77-91.

Rivacoba, Manuel de (1992): El delito de contrato simulado (Santiago, ConoSur) 107 pp.

Rodríguez Collao, Luis (2004): Delitos sexuales (reimp. de la $1^{\text {a }}$ ed., Santiago, Editorial Jurídica de Chile).

Rodríguez Devesa, José María y Serrano Gómez, Alfonso (1995): Derecho Penal. Parte Especial (18 a ed., Madrid, Dykinson).

Romero, Gladys (1998): Delito de estafa (Buenos Aires, Hammurabi).

SAVIGNY, Friedrich Carl von (1840): System des heutigen Römischen Rechts (Berlin, Veit und Comp.) Tomo III.

SCHlack, Andrés (2008): "El concepto de patrimonio y su contenido en el delito de estafa”, Revista Chilena de Derecho, vol. 35 No 2: pp. 261-292.

SchmidhäUser, Eberhard (1983): Strafrecht Besonderer Teil (2a ed., Tübingen, Mohr Siebeck).

SCHÖNE, Wolfgang (1974): Unterlassene Erfolgsabwendungen und Strafgesetz (Köln, Carl Heymanns Verlag).

Searle, John (1999): Intentionality (reimp. de la $1^{\text {a }}$ ed., Cambridge, Cambridge University Press).

Seibert, Thomas (2007): Die Garantenpflichten beim Betrug (Hamburg, Dr. Kovač).

Silva Sánchez, Jesús (2003): El delito de omisión (Montevideo - Buenos Aires, B de f).

Silva Silva, Hernán (2005): Las estafas (2a ed., Santiago, Editorial Jurídica de Chile).

Soler, Sebastián (1956): Derecho Penal Argentino (3a reimp. total, Buenos Aires, Tipográfica Editora Argentina) Tomo IV.

Soto, Miguel (1993): "Sobre los límites entre el ilícito civil y el penal. El caso de la apropiación indebida", Revista de Derecho y Jurisprudencia, Tomo XC No 1: pp. 7-27. 
Streng, Franz (2010): “Passives Tun' als dritte Handlungsform - nicht nur beim Betrug”, Zeitschrift für die gesamte Strafrechtswissenschaft (ZStW), vol. 122: pp. 1-23.

Tiedemann, Klaus (2012): “\$263”, en Laufhütte, Heinrich Wilhelm; Rissing-Van Saan, Ruth y Tiedemann, Klaus (edits.), Leipziger Kommentar. Strafgesetzbuch. Großkommen$\operatorname{tar}\left(12^{\mathrm{a}}\right.$ ed., Berlin, Walter de Gruyter) Tomo 9, Parte 1.

Tocora, Luis Fernando (1991): Derecho Penal Especial (3a ed., Bogotá, Ediciones Librería del Profesional).

Tönnies, Sibylle (1971): Die Ausdehnung des Täuschungsbegriffs durch die Konstruktion des Betruges durch schlüssiges Verhalten (Kiel, Rechtswissenschaftlichen Fakultät der Christian-Albrechts-Universität zu Kiel).

Triffterer, Otto (1971): "Abgrenzungsprobleme beim Betrug durch Schweigen - OLG Hamburg, NJW 1969, 355”, Juristische Schulung (JuS): pp. 181-184.

Tugendhat, Ernst (1976): Vorlesungen zur Einführung in die sprachanalytische Philosophie (Frankfurt am Main, Suhrkamp).

VAlERIUS, Brian (2005): "Schneller, höher, reicher? Strafbarkeit von Wett-Betrugsfällen im Sport", Zeitschrift für Sport und Recht (SpuRt): pp. 90-93.

Valle Muñiz, José Manuel (1989): El delito de estafa. Delimitación jurídico-penal con el fraude civil (reimp. de la $1^{\text {a }}$ ed., Barcelona, Bosch).

VAlle Muñiz, José Manuel (1986): "Tipicidad y atipicidad de las conductas omisivas en el delito de estafa”, Anuario de Derecho Penal y Ciencias Penales (ADPCP), No XXXIX: pp. 863-876.

VARGas, Tatiana (2010): “Engaño patrimonial' y perjuicio. Análisis desde la práctica nacional", Doctrina y Jurisprudencia Penal, No 2: pp. 51-60.

Vives Antón, Tomás y González Cussac, José Luis (2010): "Delitos contra el patrimonio y el orden socioeconómico (VII). Estafas”, en Vives Antón, Tomás et al., Derecho Penal. Parte Especial (3a ed., Valencia, Tirant lo Blanch) pp. 431-456.

Vogel, Joachim (2003): "Betrug durch konkludente Täuschung: 'Recht auf Wahrheit' oder kommunikative Verkehrssicherungspflichten?”, en: Strafrechtsprofessoren der Tübinger Juristenfakultät und Justizministerium Baden-Württemberg (edits.), Gedächtnisschrift für Rolf Keller (Tübingen, Mohr Siebeck) pp. 313-324.

Vogel, Joachim (1993): Norm und Pficht bei den unechten Unterlassungsdelikten (Berlin, Duncker \& Humblot).

Walter, Tonio (1999): Betrugsstrafrecht in Frankreich und Deutschland (Heidelberg, C. F. Müller).

WeInRICH, Harald (2006): Linguistik der Lüge (6a ed., München, Beck).

Wellmer, Albrecht (2004): Sprachphilosophie (Frankfurt am Main, Suhrkamp) 473 pp.

Wessels, Johannes y Hillenkamp, Thomas (2011): Strafrecht Besonderer Teil 2 (34a ed., Heidelberg, C. F. Müller).

Williams, Bernard (2004): Truth and Truthfulness (Princeton, Princeton University Press).

Wittig, Petra (2005): Das tatbestandsmässige Verhalten des Betrugs (Frankfurt am Main, Vittorio Klostermann).

WitTig, Petra (2011): Wirtschaftsstrafrecht (2a ed., München, Beck) 508 pp. 
Yubero, Julio (2010): El engaño en el delito de estafa (2a ed., Santiago, Editorial Jurídica Cruz del Sur).

Zugaldía Espinar, José Miguel (1988): Los delitos contra la propiedad y el patrimonio (Madrid, Akal).

\section{JURISPRUDENCIA CHILENA CITADA}

Álvarez (2008): Corte de Apelaciones de Santiago, 18 de abril de 2008 (recurso de nulidad), Causa Rol No 420-2008.

Herrera (2010): Tribunal de Juicio Oral en lo Penal de Chillán, 14 de julio de 2010, Causa RIT No 1112010.

Hurtado y otro (1999): Corte Suprema, 17 de junio de 1999 (recurso de casación en el fondo), Revista de Derecho y Jurisprudencia y Gaceta de los Tribunales, № 2 (1999), pp. 159-164.

Lobos (2011): Corte de Apelaciones de Concepción, 11 de noviembre de 2011 (recurso de nulidad), Causa Rol No 465, 2011.

Navarro (2001): Corte Suprema, 17 de julio de 2001 (recurso de casación en el fondo), Revista de Derecho y Jurisprudencia y Gaceta de los Tribunales, No 3 (2001), pp. 96-99.

Peña (2010): Corte de Apelaciones de Valparaíso, 14 de diciembre de 2010 (recurso de nulidad), Causa Rol No 1063, 2010.

Ralda (2002): Corte Suprema, 26 de junio de 2002 (recurso de casación en el fondo), Revista de Derecho y Jurisprudencia y Gaceta de los Tribunales, No 2 (2002), pp. 53-55.

Vega (2012): Corte de Apelaciones de Santiago, 13 de diciembre de 2012 (recurso de nulidad), Causa Rol N² 2993, 2012.

Vera (2005): Tribunal de Juicio Oral en lo Penal de Coyhaique, 25 de noviembre de 2005, Causa RIT No 36, 2005.

Vera (2008): Segundo Tribunal de Juicio Oral en lo Penal de Santiago, 25 de mayo de 2008, Causa RIT N 48, 2008.

\section{JURISPRUDENCIA ALEMANA CITADA}

Acusado sin indicación de iniciales (1992): Corte de Celle, 21 de julio de 1992 (recurso de casación), Strafverteidiger (StV) 1994, pp. 188-190.

Acusado sin indicación de iniciales (1979): Tribunal Federal alemán, 19 de diciembre de 1979 (recurso de casación), BGHSt 29, pp. 165-168.

A. S. y otros (2006): Tribunal Federal alemán, 15 de diciembre de 2006 (recurso de casación), BGHSt 51, pp. 165-180.

F. GmbH (2000): Tribunal Federal alemán, 8 de noviembre de 2000 (recurso de casación), BGHSt 46, pp. 196-204.

Miembro del Directorio del Servicio de Aseo de la ciudad de Berlín (2009): Tribunal Federal alemán, 9 de junio de 2009 (recurso de casación), Neue Zeitschrift für Strafrecht (NStZ): pp. 506-508. 
Representante de la empresa constructora H. \& Wo. AG (2001): Tribunal Federal alemán, 11 de julio de 2001 (recurso de casación), BGHSt 47, pp. 83-89.

\section{NORMAS CITADAS}

Código penal alemán (1872).

Código penal chileno (1874).

Código penal colombiano (2000).

Código penal español (1995).

Código penal peruano (1991).

\section{OTRAS REFERENCIAS}

Diccionario de la Real Academia Española (RAE). Disponible en: http://rae.es/drae/ [fecha de consulta: 10 de septiembre de 2013]. 